\title{
WestVirginiaUniversity
}

THE RESEARCH REPOSITORY @ WVU

Graduate Theses, Dissertations, and Problem Reports

2005

\section{Perception of safety and usability of powered hand tools}

\author{
Mun-Su Seol \\ West Virginia University
}

Follow this and additional works at: https://researchrepository.wvu.edu/etd

\section{Recommended Citation}

Seol, Mun-Su, "Perception of safety and usability of powered hand tools" (2005). Graduate Theses, Dissertations, and Problem Reports. 1644.

https://researchrepository.wvu.edu/etd/1644

This Thesis is protected by copyright and/or related rights. It has been brought to you by the The Research Repository @ WVU with permission from the rights-holder(s). You are free to use this Thesis in any way that is permitted by the copyright and related rights legislation that applies to your use. For other uses you must obtain permission from the rights-holder(s) directly, unless additional rights are indicated by a Creative Commons license in the record and/ or on the work itself. This Thesis has been accepted for inclusion in WVU Graduate Theses, Dissertations, and Problem Reports collection by an authorized administrator of The Research Repository @ WVU. For more information, please contact researchrepository@mail.wvu.edu. 
Perception of Safety and Usability of Powered Hand Tools

\section{Mun-Su Seol}

Thesis submitted to the College of Engineering and Mineral Resources

at West Virginia University

in partial fulfillment of the requirements

for the Degree of

Master of Science

in

Safety Management

Steven F. Wiker, Ph. D., Co-chair

Michael J. Klishis, Ph. D., Co-chair

Ronald C. Althouse, Ph. D.

Department of Industrial Management System Engineering

Morgantown, West Virginia

2005

Keywords: Safety, Usability, Powered Hand Tools, Perception 


\section{ABSTRACT \\ Perception of Safety and Usability of Powered Hand Tools \\ Mun-Su Seol}

The objective of this research was to identify the relationship between powered hand tool design features and risk and usability perception. The general goal of this research was to provide information that will help in the design of tools that do not create inaccurate impressions of safety or usability.

Safety and usability perception evaluations were conducted to identify which factors influence on user's safety and usability perception. Orthogonal view images of three categories of powered hand tools were developed and deployed at the web for their evaluation. One hundred and one subjects participated in this research. The estimated injury data (2001 to 2003) from CPSC and respondent's perceptions were compared to find out that there is a mismatch between their perception and injuries.

The comparison between injuries and user's safety perception indicated that there is a mismatch between both variables. The dimensions of powered hand tools studied show ed no relationship with subjects' perception. There was a strong association between safety and usability perception. Unlike other research (Wogalter, et al, 1993), there was no correlation between respondents' injury experience and their safety perception ratings during this study.

The findings showed that factors other than measured differences tool dimensions, such as experience and confidence in their ability to use tools, influenced subjects' perceptions. However, a relationship was not disclosed between observer's personal factors such as age and gender and their perception. 


\section{ACKNOWLEDGEMENTS}

Appreciation is expressed to all those who contributed in many ways to the development and completion of this thesis. Without their supports, the task would have been impossible.

I wish to sincerely express appreciation to Dr. Steven F. Wiker and Dr. Michael J. Klishis for all of their assistance and advice, as my thesis committee co-chairman. I would also like to thank Dr. Ronald C. Althouse for being on my thesis committee. Very special gratitude is expressed to Dr. Steven F. Wiker for getting me interested in pursuing this thesis with an interesting topic.

In addition, I would like to extend recognition to the author's wife, Ju Mi-Jeong, for her patience and understanding throughout this period of graduate study and his children, Jun-Hyung and Ye-Won, for their love. 


\section{CONTENTS}

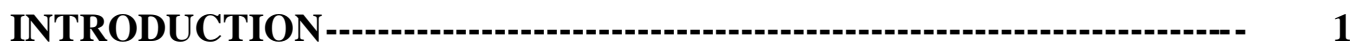

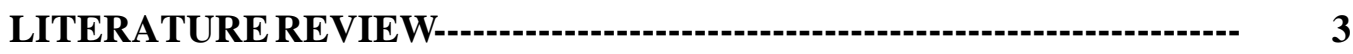

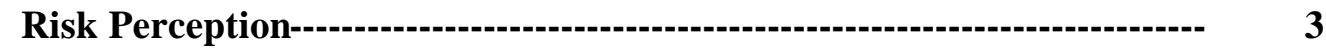

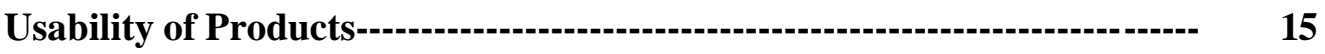

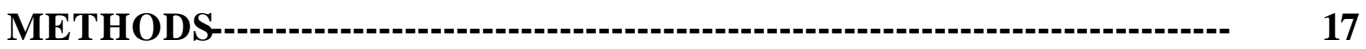

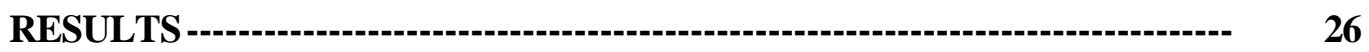

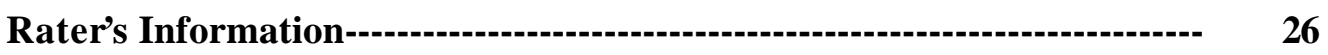

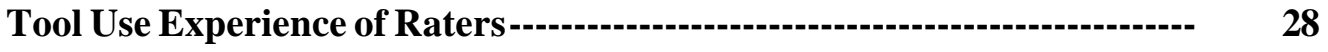



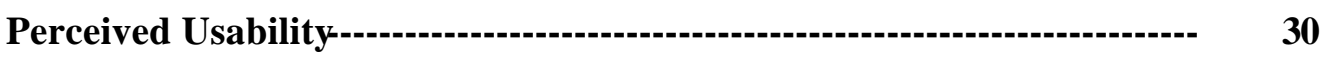

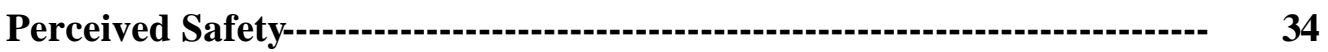

Paired Comparison Tests of Difference between Usability Ratings of

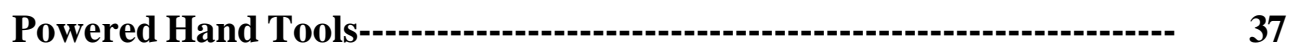

Paired Comparison Tests of Difference between Safety Ratings of

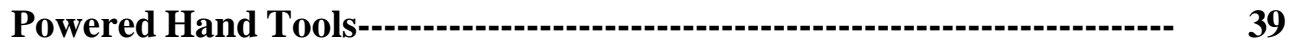

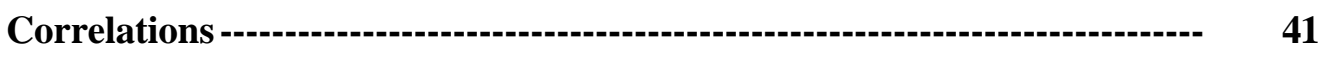

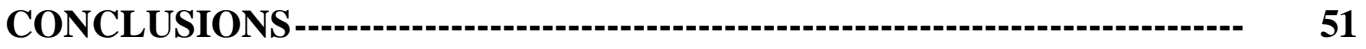

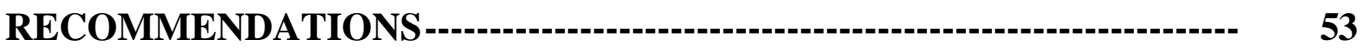

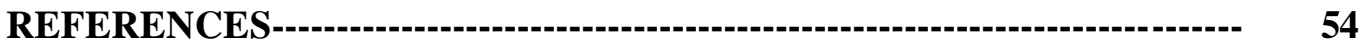

\section{APPENDICES}

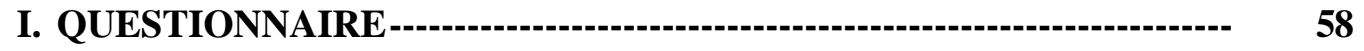

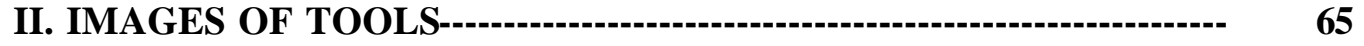

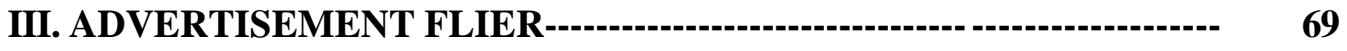

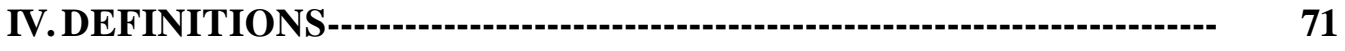

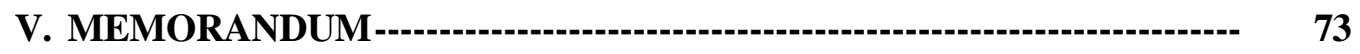


LIST OF TABLES

Table

1. Dimensions and Their Means of Circular Saws Studied,

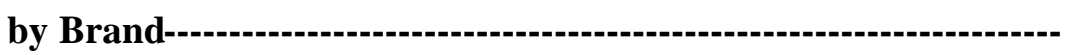

2. Dimensions and Their Means of Powered Drills Studied,

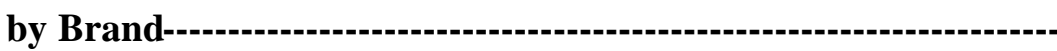

3. Dimensions and Their Means of Powered Nailers Studied, by Brand-

4. Frequency and Mean Percent of Powered Hand Tools Use

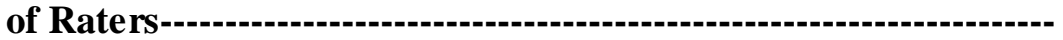

5. Means with Standard Deviations of Rater's Confidence Ratings

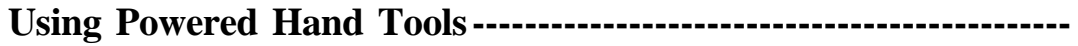

6. Means with Standard Deviations and Modes of Perceived Usability Ratings of Different Brands of Circular Saws, Drills,

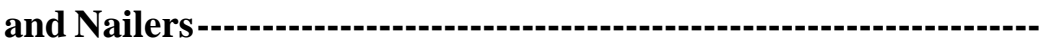

7. Estimated Marginal Means of Perceived Usability Ratings of Different Brands, Genders, and Age Groups of Circular Saws--

8. Means with Standard Deviations and Modes of Perceived Safety Ratings of Different Brands of Circular Saws, Drills, and Nailers

9. Paired Comparison Tests of Differences between Usability

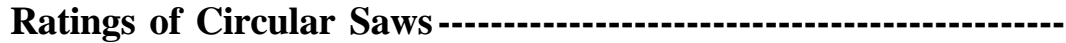

10. Paired Comparison Tests of Differences between Usability

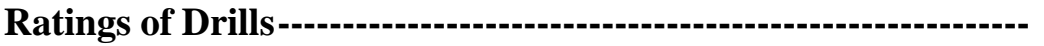

11. Paired Comparison Tests of Differences between Usability Ratings of Nailers

12. Paired Comparison Tests of Differences between Safety

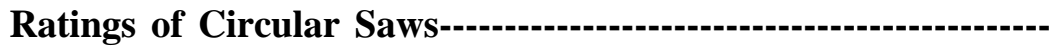


13. Paired Comparison Tests of Differences between Safety

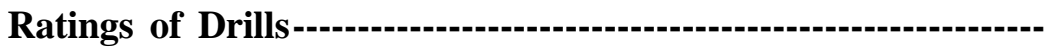

14. Paired Comparison Tests of Differences between Safety

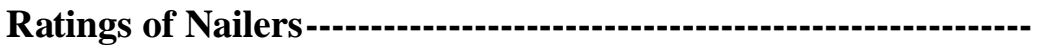

15. Correlations between Respondents' Personal Factors and Perceived Safety/Usability for Circular Saws ---------------------

16. Correlations between Respondents 'Personal Factors and

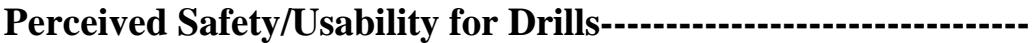

17. Correlations between Respondents 'Personal Factors and Perceived Safety/Usability for Nailers

18. Correlations between Tool Dimensions and Perceived Safety/Usability of Raters for Circular Saws --.---.---.---.---.---

19. Correlations between Tool Dimensions and Perceived

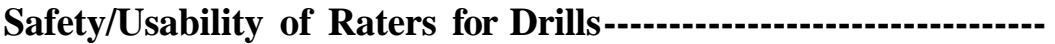

20. Correlations between Tool Dimensions and Perceived

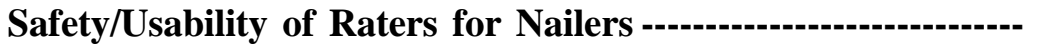




\section{LIST OF FIGURES}

Figure $\quad$ Page

1. Distributions of Raters’ Ages Participated in This Experiment------ 17

2. Comparison of the Dimensions of Circular Saws Studied,

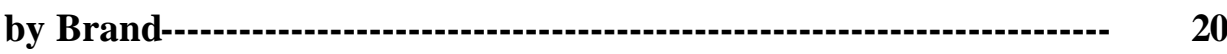

3. Comparison of the Dimensions of Drills Studied, by Brand--------- 22

4. Comparison of the Dimensions of Nailers Studied, by Brand------- 24

5. Comparison between Safety and Usability Trainings Experience

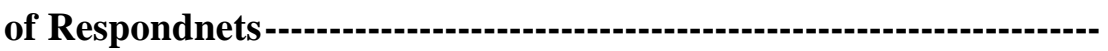

6. Percent of Raters that Experienced Injury with Powered Hand

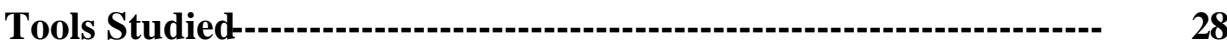

7. Estimated Marginal Means of Perceived Usability Ratings

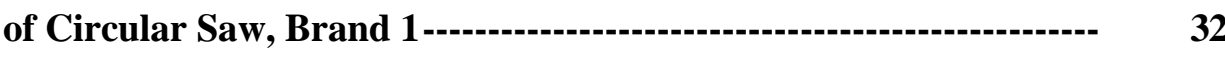

8. Estimated Marginal Means of Perceived Usability Ratings

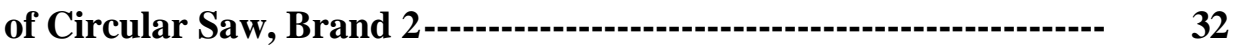

9. Estimated Marginal Means of Perceived Usability Ratings

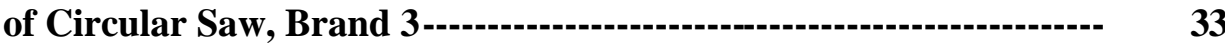

10. Comparison between Mean Ratings of Perceived Safety and Usability of Circular Saws, by Brand----------------------------- 35

11. Comparison between Mean Ratings of Perceived Safety and Usability of Drills, by Brand ------------------------------------ 36

12. Comparison between Mean Ratings of Perceived Safety and Usability of Nailers, by Brand------------------------------------- 36

13. Scatter Plot Showing Relations between Perceived Safety and Usability Ratings of Circular Saw------------------------------------ 
14. Inter-correlations between Personal Factors and Perceived

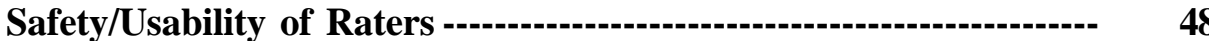

15. Interrelationship Found between Reported Injuries with Various

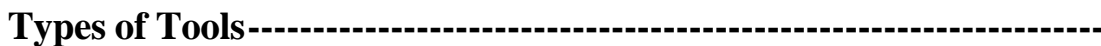

16. Correlogram Demonstrating that Subjects Who were Experienced with Tools Addressed in the Questionnaire 


\section{INTRODUCTION}

Over the past decades, companies and individual customers have been accustomed to the safety of product and services they made or use. Most industries have invested their resources to reduce or prevent losses from incidents due to products design flaws. When manufactures have designed in, or through poor manufacturing unreasonably hazardous product, liability claims have resulted.

On the other hand, most of the individual consumers have tried to recover through lawsuits losses occurred by unreasonably safe product provided by manufacturers during their jobs. According to Jury Verdict Research's report issued on January 2004, the median and mean compensatory jury award for product liability cases in the U.S. was $\$ 700,000$ and $\$ 3,391,845$ respectively (Jury Verdict Research, 2004).

The U.S. Consumer Product Safety Commission (CPSC) is charged with protecting the public from unreasonable risks of serious injury or death from more than 15,000 types of consumer products under the agency's jurisdiction. Deaths, injuries and property damage from consumer product incidents are estimated to cost the nation more than $\$ 700$ billion annually (CPSC, 2004).

According to CPSC, 4,639 deaths were associated with the use of certain consumer products from October 1, 1999 to September 30, 2000. Estimates of hospital emergency room treated injuries associated with the use of certain consumer products were 14,211,020 with estimated emergency room treatment cost in relation 
with consumer product injuries at 339,050 million dollars (CPSC 2002).

It is clear that people do not act with the same degree of caution with all of the products that they encounter (Wogalter et al., 1999). Several studies suggest that cautionary behavior is inf luenced by the perceived hazard associated with a product (Godfrey et al., 1983, Larue \& Cohen, 1987, and Wogalter et al., 1991).

If there is a mismatch between consumers' perception and actual risk or usability, such mismatches may promote accidents and injuries. The objective of this research is to examine the relationship between tool design and other factors (elaborate) and subject's perception of safety and usability selected randomly such as Circular Saws, Drills and Nailers. This will contribute for manufacturers to develop design modified and intervention strategies that would reduce injuries related to the products. The general goal of this research is to provide information that will help in the design of tools that do not create inaccurate impressions of safety or usability. 


\section{LITERATURE REVIEW}

\section{Risk Perception}

Risk is defined as "A measure of both the probability and the consequences of all hazards of an activity or condition". All risk concepts have one element in common; a distinction between reality and possibility. A discussion around the uncertainty of a situation has prevailed and Rosa (2003) defined risk as "a situation or an event where something of human value (including humans themselves) is a stake and where the outcome is uncertain". Hence, uncertainty is closely related to risk and in many theories of behavior, psychological uncertainty is assumed to be an important mediator of human responses in situations with unknown outcomes (Sjoberg et al., 2004). Other working definitions in current use are: "the probability that danger is present;" "the probability that an accident will occur;" "a subjective evaluation of relative failure potential;" and "the probability of experiencing a loss due to abnormal events.”(Jack, 1991).

Accor ding to Consumer Product Safety Commission (CPSC), deaths, injuries and property damage from consumer product incidents are estimated to cost the nation more than $\$ 700$ billion annually (CPSC, 2004). Four thousand six hundred and thirty nine $(4,639)$ of deaths were associated with the use of certain consumer

products from October 1, 1999 to September 30, 2000. Estimates of hospital emergency room treated injuries associated with the use of certain consumer products were 14,211,020 with estimated emergency room treatment cost in relation 
with consumer product injuries at 339,050 million dollars (CPSC, 2002). Estimated injuries in U.S. by circular saws, powered drills, and nailers were 33,723, 38,086, and 45,482 during 2001 to 2003 respectively (CPSC, 2001, 2002, and 2003).

There are many definitions for risk. For safety and health a common definition of risk infers a quantitative concept. Risk is the product of frequency and severity of potential losses. Frequency is the probability of occurrence of an event, such as once per week or per year. Severity is the potential loss when an event occurs. The loss may be expressed in human term, such as loss of life, serious injury, serious illness, number of cancer cases and so forth. The loss may also be expressed in financial term, like dollars lost, cost to replace lost equipment, cost of downtime or cost to replace facilities. Loss may be expressed in legal term, such as claim, lawsuits and liability (Brauer, 1996).

Risk perception is one's opinion of the likelihood of risk associated with performing a certain activity or choosing a certain lifestyle. Risk perception may be influenced by many factors some sociological, some anthropological and some psychophysical, but the result is that people vary considerably in which risks they consider acceptable and which they do not even when they may agree on the degree of risk involved. For example, to many people air travel represents the very model of a low-risk form of transport. For others, with no fear of traveling large distance by car or train, the prospect of a flight, even with a well-respected commercial airline, can be a nightmare. But as demonstrated by the probability of death concerning transport across the United States, car trip is 1 in 14,000 , train trip is 1 in $1,000,000$, and airline trip is 1 in $10,000,000$, which is actually one of the safest forms of 
transport (Brian, 2002).

The most widely held theory of risk perception we call the knowledge theory: the often implicit notion that people perceive technologies (and other things) to be dangerous because they know them to be dangerous. Another commonly held cause of risk perception follows from personality theory: some individuals love risk-taking so they take many risks, while others are risk averse and seek to avoid as many risks as they can. The third set of explanations for public perceptions of danger follow two versions of economy theory. In one, the rich are more willing to take risks stemming from technology because they benefit more and are somehow shield from adverse consequences. The poor presumably feel just the opposite. Other explanations for public reaction to potential hazards are based on political theory. These accounts view the controversies over risk as struggle over interests, such as holding office or party advantage. The hope for explanatory power in such approaches to risk perception is thus placed on social and demographic characteristics such as gender, age, social class, liberal-conservative ratings, and/or adherence to political parties. Viewing individuals as the active organizers of their own perceptions, cultural theorists have proposed that individuals choose what to fear (and how much to fear it), in order to support their way of life. In this respective, selective attention to risk, and preferences among different type of risk taking (or avoiding), correspond to cultural biases-that is, to worldviews or ideologies entailing deeply held values and beliefs defending different patterns of social relations (Karl and Aaron, 1996)

Much research has been conducted in trying to understand people's concept of 
risk. What make one individual take more or less risks? In 1979, Slovic, Fischhoff, and Lichtenstein have defined a number of factors that affect the way people perceive a risk. One factor is whether the risk is voluntary or not. Another important factor in perceiving risk is whether the consequences of an accident are chronic or catastrophic. Perceived catastrophic consequences raise the risk concern. Another factor is whether the fate is certain to be fatal or not certain to be fatal. If the danger is immediate and not delayed, many people feel that the risk is greater. The last factor is whether the risk is new or old. The newer it is, the riskier it is perceived to be.

In 1993, Wogalter, Brems, and Martin examined people's accuracy in judging the risk of common consumer products. In two experiments, participants estimated the frequency of product-related injuries at a quick pace, slow pace, and following analysis of accident scenarios. Participants' estimate of injury was then compared to objective injury rates complied by the U.S. Consumer Product Safety Commission. The result showed that participants were able to assess relative level of risk quickly and accurately, but additional time and analysis had no effect on estimation accuracy.

The body of accident research data offers numerous examples of risky decision making and permits several conclusions to be drawn about behavior of people under conditions of risk (Zeitlin, 1994).

The subjective assessment of risk and the actual hazard are not linearly related. Cohen et al. (1956), in a study of experienced bus driver, showed that in situations in which the probability of an accident was low, driver assumed the risk to be greater 
than it actually was, but in a situations when the probability of an accident was high, driver assumed the risk to be lower than it actually was. Zeitlin (1967 and 1975), in studies of railway and marine accidents, demonstrated that crew members violated rules in a way that tended to minimize mildly unpleasant high-probability event at the risk accepting highly unpleasant low - probability event. Wogalter, Desaulniers, and Brelsford, (1987) found that the subjective assessment of risk decreases as familiarity with the hazard increases (Zeitlin, 1994).

The acceptance of risk depends on the degree of choice or perceived control the individual has in the situation. Starr (1969 and 1972) offered considerable data from a number of fields to show that individuals are far more willing to assume voluntary risks than involuntary risks. He argued that the several orders-of-magnitude greater willingness to accept voluntary risk is not based on a differential assessment of actual hazard but, rather, on the greater utility and/or satisfaction that riskacceptant behavior offers the individuals. Solvic (1978) suggested that the perception of control increases the willingness to assume risk (Zeitlin, 1994).

Individual and social factors - including personality, sex, age, experience, and culture-influence risk-taking behavior. Rockwell, Galbreath, and Center (1961), in a series of simulator studies, showed that risk-taking behavior was influenced by sex, personality, and overall anxiety level. The most important factor was experience with the hazard. Wellford (1959), in a comprehensive study of aging, discussed the changes in risk taking behavior of the elderly. Tamerin and Resnik (1972) detailed personality differences involved in healthy versus neurotic risk taking. Weiss (1991) reported that risk acceptance varied by sex: $45 \%$ of men and $27 \%$ of women enjoyed 
the sensation of danger (Zeitlin, 1994).

Perception is a key component of human behavior. It is the mechanism with which a person evaluates inputs form the external environment, which, in turn, determines his/her behavioral response. In conjunction with personality or disposition, attitudes and previous experiences, perceptions comprise a person's unique appraisal of the environment. These perceptions are critical antecedents that precede behavior as they form a vital part of the human survival instinct. A person's risk-taking propensity is determined by his/her perception of the situation, past experience in similar situations and his/her personality. Risk is essentially a subjective construct that refers to the possibility of harm or loss within a particular situation. This, risk perception first requires someone to identify the existence of a possible threat, which does not always occur (Cooper, 2003).

Allied with intrinsic and extrinsic motivation is another important influence on risk taking: risk perception. In ordinary usage, risk perception is the awareness or discernment of the potential for harm or loss. If, because of biology, physiology and/or the social milieu, an individual is already predisposed to taking risks, risk perception can be the determining factor in deciding to take a chance. According to Slovic, individuals generally evaluate the "riskiness" of a risk based on the benefit they see attached to it, the voluntariness of exposure, familiarity with the risk, control over it, and catastrophic potential, By virtue of factor analysis, even these categories can be reduced to two: 1) how dread is the risk; and 2) how unknown is the risk. Solvic comments that perception and acceptance of risk spring from social and cultural factors-the influence of family, friends, fellow workers and respected 
officials; or the influence of a social group that emphasizes or downplays risks as a means of maintaining and controlling itsef. He emphasizes that unless safety and health policy makers understand risk perceptions, a well-intentioned policy may be totally ineffective (James, 1991).

One broad strategy for studying perceived risk is to develop taxonomy for hazards that can be used to understand and predict responses to their risks. A taxonomy scheme might explain, for example, people 's extreme aversion to some hazards, their indifference to others, and the discrepancies between these reactions and opinions of experts. The most common approach to this goal has employed the psychometric paradigm, which uses psychological scaling and multivariate analysis techniques to produce quantitative representations or "cognitive maps" of risk attitudes and perceptions. Within the psychometric paradigm, people make quantitative judgments about the current and desired riskiness of diverse hazards and desired level of regulation of each. These judgments are then related to judgments about other properties, such as (i) the hazards status on characteristics that have been hypothesized to account for risk perceptions and attitudes (for example, voluntariness, dread, knowledge, controllability), (ii) the benefits that each hazard provide to society, (iii) the number of deaths caused by the hazard in an average year, and (iv) the number of deaths caused by the hazard in a disastrous year (Solvic, 1987).

Star (1969) concluded that acceptability of risk from an activity is roughly proportional to the third power of the benefits for that activity, and the public will accept risks from voluntary activities (such as skiing) that are roughly 1000 times as 
great as it would tolerate from involuntary hazards (such as food preservatives) that provide the same level of benefits. Fischhoff et al. (1978) conducted an analogous psychometric analysis of questionnaire data, resulting in "expressed preferences". They have shown that the concept 'risk means different things to different people. When experts judge risk, their responses correlate highly with technical estimates of annual fatalities. Lay people can assess annual fatalities if they are asked to (and produce estimates somewhat like the technical estimates). However, their judgments of 'risk' are related more to other hazard characteristics (for example, catastrophic potential, threat to future generations) and, as a result, tend to differ form their own estimates of annual fatalities (Solvic, 1987).

Many of qualitative risk characteristics are correlated with each other, across a wide range of hazards. For exa mple, hazards judged to be 'voluntary' tend also to be judged as "controllable"; hazards whose adverse effects are delayed tend to be seen as posing risks that are not well known, and so on. The research has shown that lay people's risk perception and attitudes are closely related to the position of a hazard within certain type of factor space such as dread risk, unknown risk and the number of people exposed to the risk. In contrast, experts' perceptions of risk are not closely related to any of various risk characteristics or factors derived from these characteristics. Instead, experts appear to see riskiness as synonymous with expected annual mortality (Solvic, 1987).

Important contributions to our current understanding of risk perception have come from geography, sociology, political science, anthropology, and psychology. Geographical research focused originally on understanding human behavior in the 
face of natural hazards, but it has since broadened to include technological hazards as well. Sociological and anthropological studies have shown that perception and acceptance of risk have their roots in social and cultural factors. Short argues that response to hazards is mediated by social influence transmitted by friends, family, fellow workers, and respected public officials. Douglas and Wildavsky assert that people, acting within social groups, downplay certain risks and emphasize others as a means of maintaining and controlling the group. Psychological research on risk perception originated in empirical studies of probability assessment, utility assessment, and decision-making processes (Solvic, 1987).

One frequently advocated approach to broadening people's perspectives is to present quantitative risk estimates for a variety hazards, expressed in some unidimensional index of death or disability, such as risk per hour of exposure, annual probability of death, or reduction in life expectancy. Even though such comparisons have no logically necessary implications for acceptability of risk, one might still hope that they would help improve people's intuitions about the magnitude of risk (Solvic, 1987).

A growing body of knowledge on what is usually called "risk perception" helps illuminate the values involved in the evaluation of different quality of hazards. Analysis consistently shows that people's risk ratings are a function not only of average annual fatalities according to the best available estimates, but also of the attributes of the hazards and benefits associated with a technology, activity, or substa nce. In particular, the studies show that certain attributes of hazards, such as the potential to harm large number of people at once, personal uncontrollability, 
dreaded effects, and perceived involuntariness of exposure, make those hazards more serious to the public than hazards lack those attributes (National Research Council, 1989).

There are other factors that are related to people 's perception of hazardousness of a product (Wogalter et al., 1987). The more familiar the person with the product and the more contacts has with the product, the less hazardous the product is perceived to be. Also the more technologically complex the product, the more hazardous it is perceived to be.

Risk perception is the subjective assessment of the probability of a specified type pf accident happening and how concerned we are with the consequences. To perceive risk includes evaluations of the probability as well as the consequences of a negative outcome. Perception of risk goes beyond the individual, and it is a social and cultural construct reflecting values, symbol, history, and ideology (Weinstein, 1989).

Starr (1969) investigated risks in some details and found that society seemed to accept risks to the extent that they were associated with benefits, and was what he termed voluntary (Sjoberg et al,. 2004).

Consumer risk perceptions are widely understood to be a major factor influencing consumer behavior. Defined as "a consumer's subjective feeling that there is some probability that a choice may lead to an undesirable outcome", consumer risk perception have been shown to include time, financial, performance, 
physical, psychological and social risk types, that may act alone or in combination to represent a consumer's overall risk perception (Brown and O'Cass, 2004).

In terms of research related to consumer risk perceptions, a major stream has focused on its relationship with information search. From a consumer perspective, information search involves the acquisition of information either internally (using information stored in memory) or externally (seeking information from the environment that has not previously been acquired or is unable to be recalled form the memory) (Schmidt and Spreng, 1996). Overall finding in the literature suggest that external information search is a risk reducing activity used by consumers across a broad variety of consumer goods such as sunglasses and automobiles (Chaudhuri, 2000). That is, when a consumer perceives greater risk associated with a decision they engage in a greater amount of sea rch for information associated with the object (Brown and O 'Cass, 2004).

There are several sources of bias that appear to influence perception risk. People appear to overestimate the value of their own experience. If they have not been injured or have not known people who were injured, they tend to underestimate the risk involved. Tversky and Kahneman (1973) refer to availability heuristic that people use or estimate the risks. People tend to give higher probabilities to events they can easily remember. News stories also bias perception of risk. People grossly overestimate risks with associated with situations or products that have received considerable attention in the media, although the media tends to report on unusual risks rather than normal risks. 
A study by Young, Wogalter, and Brelsford (1992) found that the perceived severity of a hazard has a greater impact on risk estimation than does the probability of the hazard.

Whether people actually interpret differences between signal words of warning label of products is equivocal, considering the results showed by related researches. Leonard et al., (1986) reported no reliable differences between risk ratings of the term DANGER, WARNING, and CAUTION. In addition, Wogalter et al., (1987) found no difference between the term WARNING and NOTE in a behavioral effectiveness study. In 1990, Wogalter and Silver found that DEADLY, DANGER, WARNING, CAUTION, CAREFUL, ATTENTION, NOTICE, and NOTE conveyed the greatest to least hazard respectively. In 1994, Wogalter et al. found that the presence of a signal word increased perceived product hazard compared with its absence. Significant differences were noted between extreme terms (e.g., NOTE and DANGER) but not between terms usually recommended in warning design guidelines (e.g., CAUTION and WARNING).

\section{Usability of Products}

Usability is the condition of a product, system or service being used for human 
use. A useful product is a good fit between need and solution, between human user and artifact. A product that is useful makes it possible for an individual to perform a task more reliably and with fewer errors. Useful products are easier to learn and more satisfying to use. Usability pertains to all aspects of a product including hardware, software, menus, icons, message, manual, quick reference, online help and training (Christopher, 2003).

The goal of many usability studies is to identify design problems and recommended product changes (to either the current product or future products) based on the design problems (James, 1994).

Stanton and Barber $(1992,1996)$ suggested that the factors below serve to shape the concept of usability and define its scope:

- Learnability: A system should allow users to reach acceptable performance levels within a specified time.

- Effectiveness: Acceptable performance should be achieved by a defined proportion of the user population, over a specified range of tasks and in a specified range of environments.

- Attitude: Acceptable performance should be achieved within acceptable human costs, in terms of fatigue, stress, frustration, discomfort and satisfaction.

- Flexibility: The product should be able to deal with a range of tasks beyond those first specified.

- Task match: In addition to the LEAF (Learnability, effectiveness, attitude, flexibility) percepts set out above, a usable product should exhibit an 
acceptable match between the functions provided by the system and the needs and requirements of the user.

- Task characteristics: The frequency with which a task can be performed and degree to which the task can be modified, e.g. in terms of variability of information requirements.

- User characteristics: Another section which should be included in a definition of usability concerns the knowledge, skills and motivation of the user population.

The ISO 9241 defines usability as the extent to which a product can be used by specified users to achieve specified goals with effectiveness, efficiency and satisfaction in a specified context of use (Baber, 2002)

Functionality of a consumer product is no longer the only competitive factor in the product design. Product usability should also be treated equally important to make product successful in the market. The traditional concept of usability has been expanded to include subjective user satisfaction along with user performance. Examples include a concept of product usability, emotional usability, seductive user interface design, and pleasure of use. Common to those concepts is to design a product that corresponds to consumer taste and preference (Han and Hong, 2003).

\section{METHODS}

Subjects: The sample used for this study included from carpenters, students and 
residents in the United States who participated voluntarily. Subjects for the study were 69 male and 32 female who responded to an advertisement posted in the public bulletin board. As shown Figure 1, 20 to 29 years took more than $65 \%$ of them. They averaged 30.8 years of age.

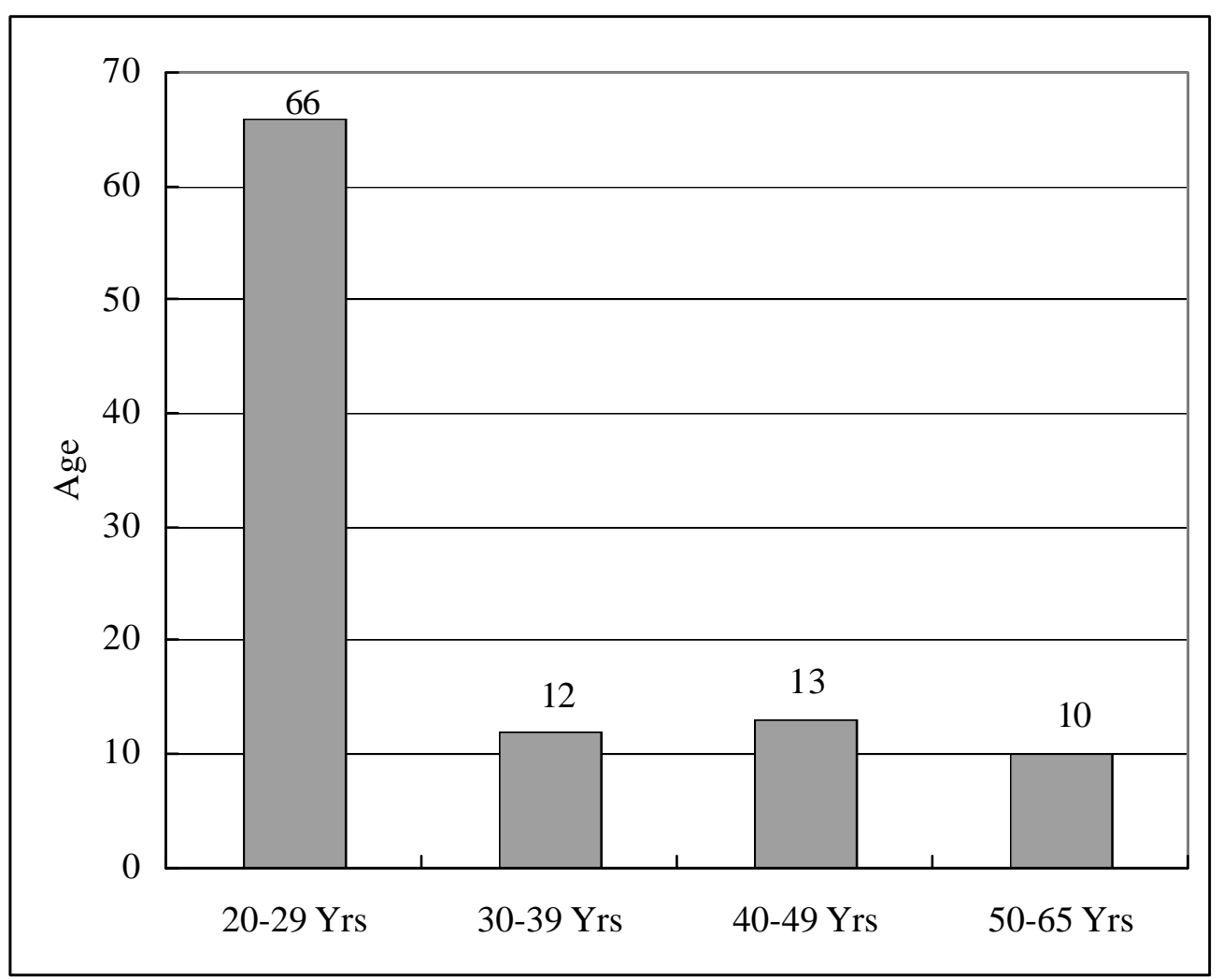

Figure 1. Distribution of the Ages of Raters Participated in this Experiment

Materials: Three powered hand tool categories such as Circular Saws, Drills, and Nailers were taken for this research. Three Circular Saws, three Drills and two Nailers were selected from those product categories. The author took orthogonal pictures of products that have different kinds of safety and usability features such as size and shape of handle, product volume, size of trigger switch, and so on. The author eliminated or corrected brand name and color of products using computer 
software, which may contribute to consumers' prejudiced evaluation. The author measured specific dimension of main parts of three kinds and eight of powered hand tools that may influence on consumers' risk perception and usability assessment. Tables 1 to 3 and figures 2 to 4 present measured dimensions of tools studied. 
Table 1. Dimensions and Their Means of Circular Saws Studied, by Brand

\begin{tabular}{|c|c|c|c|c|}
\hline Measured Part & Brand 1 & Brand 2 & Brand 3 & Mean \\
\hline Handle Bottom Circumference & 12.3 & 13 & 11.3 & 12.2 \\
\hline Handle Middle Circumference & 13.2 & 14.2 & 12 & 13.1 \\
\hline Handle Trigger Circumference & 15.7 & 15 & 15 & 15.2 \\
\hline Handle Length & 9 & 13 & 12.5 & 11.5 \\
\hline Trigger Length & 3 & 2 & 2.5 & 2.5 \\
\hline Trigger Width & 1.5 & 1 & 1 & 1.1 \\
\hline Tool Length & 35 & 30 & 29 & 31.3 \\
\hline Tool Height & 13 & 21.5 & 23 & 19.2 \\
\hline Tool Width & 21 & 26 & 24 & 23.7 \\
\hline Blade Guard Diameter & 22 & 24 & 23.5 & 23.2 \\
\hline Second Handle Width & 9 & 7 & 6.5 & 7.5 \\
\hline Second Handle Circumference Right & 10.8 & 14 & 12.7 & 12.5 \\
\hline Second Handle Circumference Left & 10.8 & 13 & 12.7 & 12.2 \\
\hline Second Handle Height & 4.5 & 6 & 7 & 5.8 \\
\hline
\end{tabular}

Unit: $\mathrm{cm}$ 


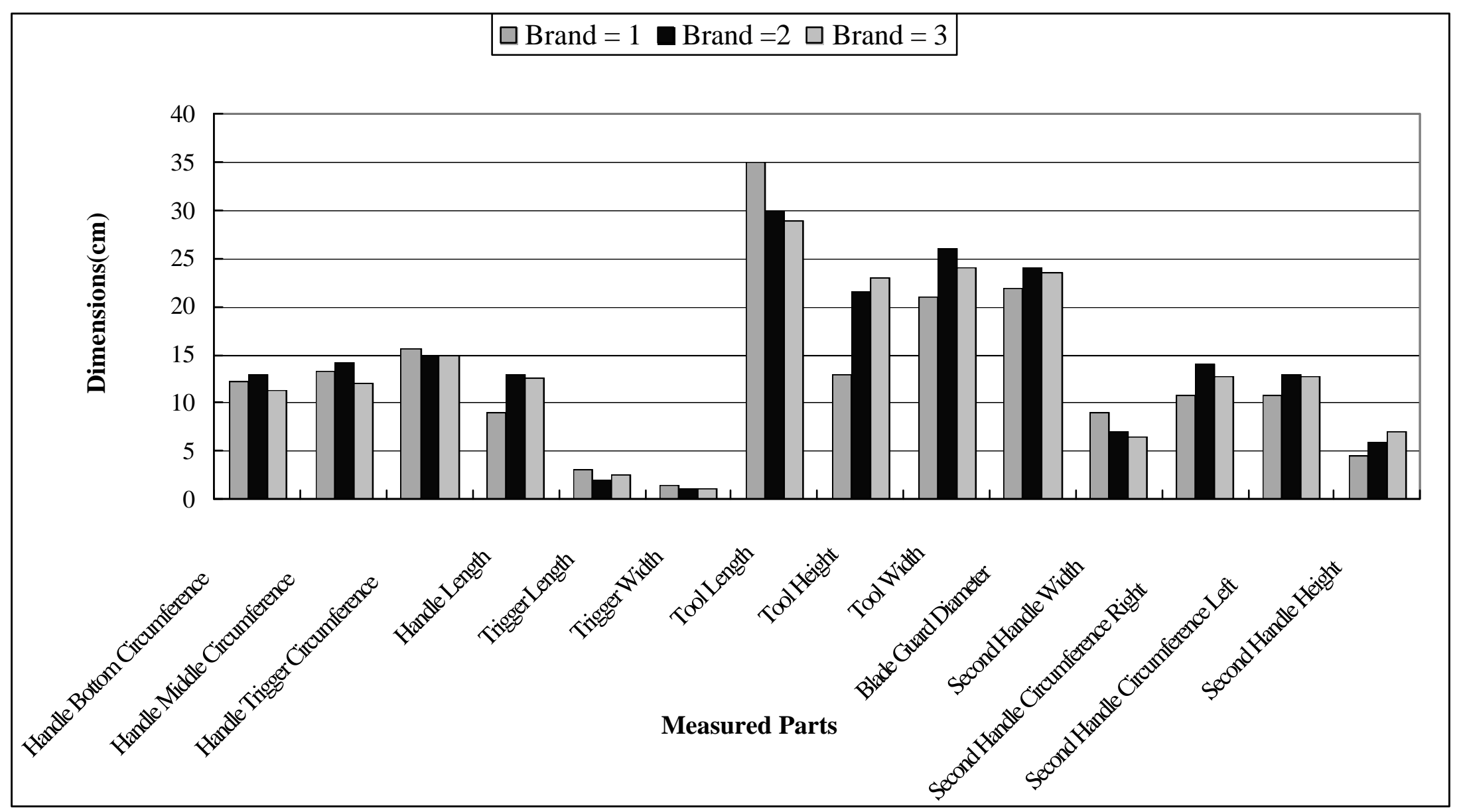

Figure 2. Comparison of the Dimensions of Circular Saws Studied, by Brand 
Table 2 Dimensions and Their Means of Powered Drills Studied, by Brand

\begin{tabular}{|c|c|c|c|c|}
\hline Measured Parts & Brand 1 & Brand 2 & Brand 3 & Mean \\
\hline Handle Bottom Circumference & 12.2 & 12.6 & 14.5 & 13.1 \\
\hline Handle Middle Circumference & 13.2 & 13.5 & 14 & 13.5 \\
\hline Handle Trigger Circumference & 15.5 & 16.9 & 16.2 & 16.2 \\
\hline Handle Length & 11.5 & 10 & 8 & 9.8 \\
\hline Trigger Length & 3 & 3 & 3 & 3 \\
\hline Trigger Wide & 1.5 & 2 & 2 & 1.8 \\
\hline Tool Length & 41 & 27 & 27 & 31.6 \\
\hline Tool Height & 14 & 22 & 25.5 & 20.5 \\
\hline Tool Width & 7 & 7.5 & 6 & 6.8 \\
\hline Barrel Circumference & 25 & 26.2 & 18.6 & 23.2 \\
\hline Second Handle Length & 27 & 11 & N/A & 19 \\
\hline Second Handle Circumference Middle & 10.5 & 10 & N/A & 10.2 \\
\hline Second Handle Circumference Flange & 8.7 & 9 & N/A & 8.8 \\
\hline
\end{tabular}

Unit: $\mathrm{cm}$ 


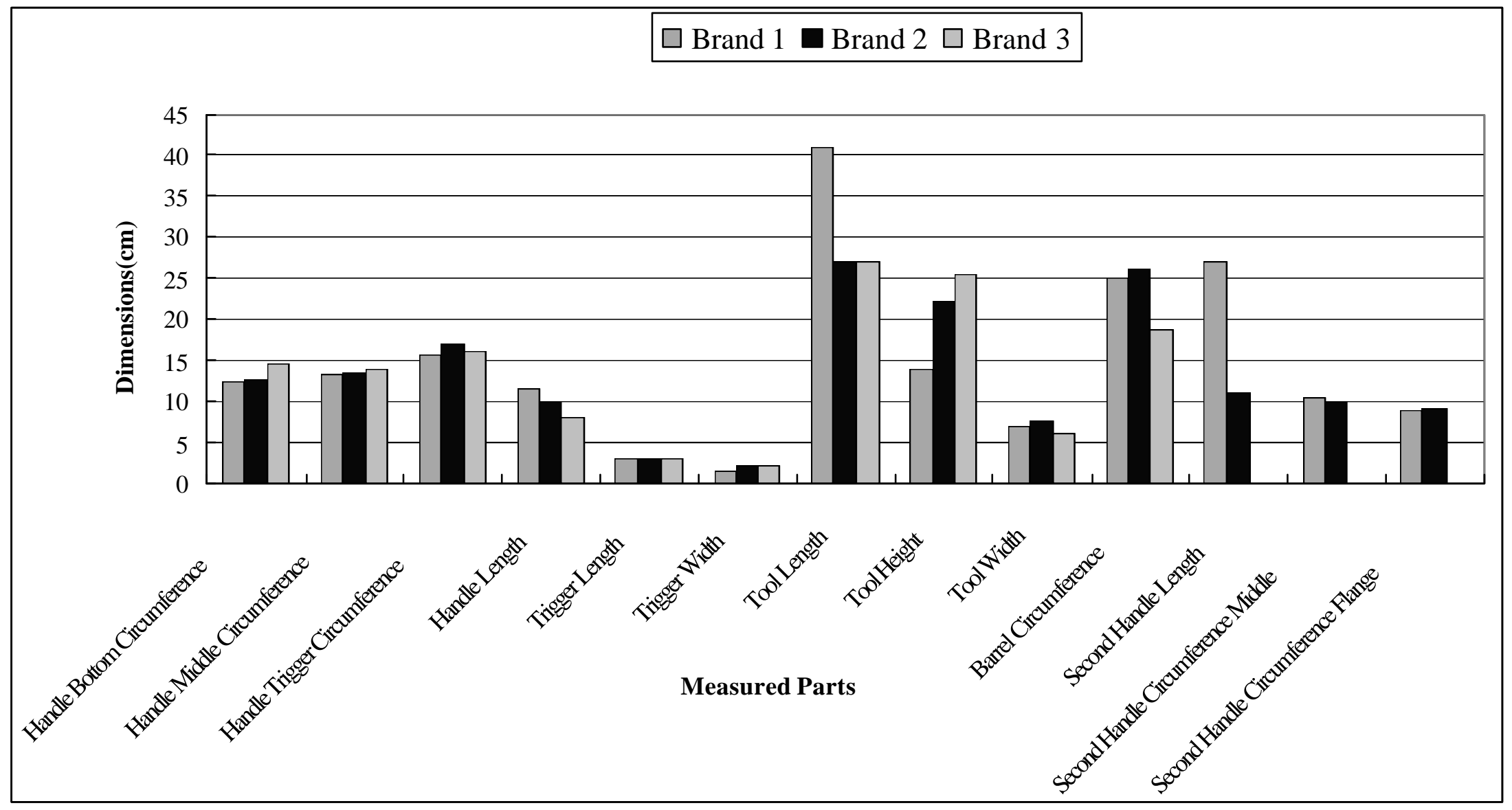

Figure 3. Comparison of the Dimensions of Powered Drills Studied, by Brand 
Table 3. Dimensions and Their Means of P owered Nailers Studied, by Brand

\begin{tabular}{lccc}
\hline \multicolumn{1}{c}{ Measured Parts } & Brand 1 & Brand 2 & Mean \\
\hline Handle Circumference Bottom & 12.2 & 11.8 & 12 \\
Handle Circumference Middle & 14.2 & 13.5 & 13.8 \\
Handle Circumference Trigger & 15.5 & 12.6 & 14.1 \\
Handle Length & 9 & 20 & 14.5 \\
Trigger Length & 4.8 & N/A & 4.8 \\
Trigger Width & 1.5 & N/A & 1.5 \\
Tool Length & 20.5 & 32 & 26.3 \\
Tool Height & 19 & 29 & 24 \\
Tool Width & 9 & 7.6 & 8.3 \\
Barrel Circumference & 22 & N/A & 22 \\
\hline
\end{tabular}

Unit: cm 


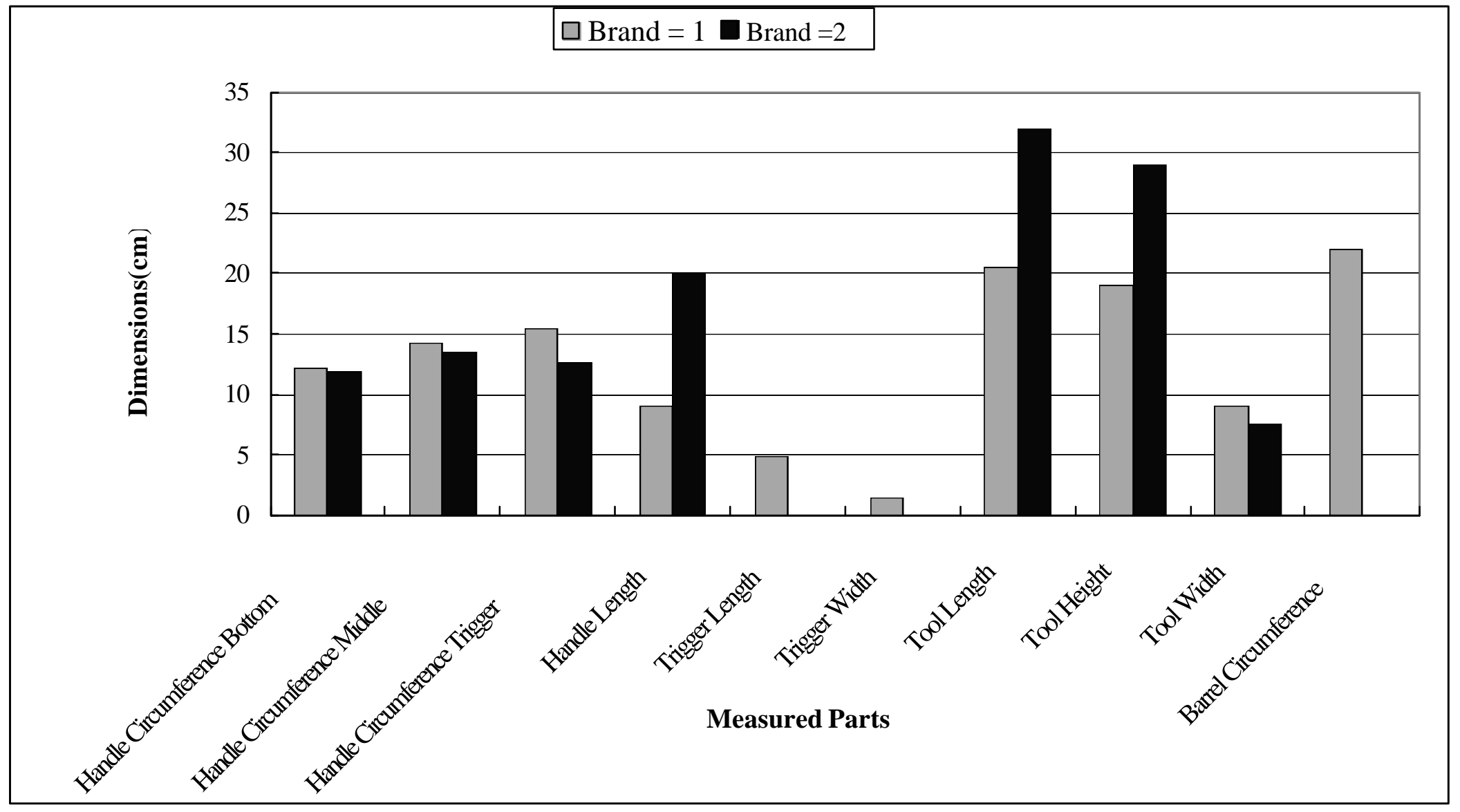

Figure 4. Comparison of the Dimensions of Nailers Studied, by Brand 
Three pictures of each product taken from front, side and plane view were used for subjects to evaluate their perceived safety or usability. All pictures' size was rescaled to compensate errors due to different distance between camera and products when they were taken.

Questionnaire: A questionnaire with 29 questions was developed for this research. The questionnaire contained instruction, purpose of this research for responders. Three pictures of each product were employed in the questionnaire. Each question has zero to ten scales for the estimation of subjects' safety and usability. The questionnaire also has questions that were consisted of personal information such as his/her age, gender, and use and injury experience level of powered hand tools on which may influence subjects' risk perception and usability judgment respectively.

Procedures: Survey questionnaire with product pictures developed for this research was deployed on the Web Site. An advertisement that promotes to participate voluntarily in survey was posted at several public places such as university library and computer lab, customer supermarket, construction site, and apartment bulletin board about two weeks. Each participant was instructed to evaluate his/her subjective feeling for question provided in the questionnaire. Data automatically collected from computer software program as soon as subjects finish their responses. The advertisement flier was posted about two weeks. Then, the data was analyzed specifically to identify correlation between responders' safety and usability assessment for each product, and to locate whether any mismatch exists between subjects' perceived risk degree and actual product hazard. 


\section{RESULTS}

One hundred one subjects voluntarily responded in this study during two weeks. Almost 60 percent of respondents responded that they had had a certain kind of safety and usability training such as OJT, college course, graduate, or short course. According to the result of question concerning rater's tool use experience, about 30 percent of respondents used a powered hand tool monthly at least. Analyses initially compared two mean ratings with respect to perceived safety and usability. These means were slightly different across all studied tools as shown in the Table 6 and Table 8 . As indicated in Table 15 to Table 20, safety and usability perception showed strong positive relations, and a relationship between safety or usability perception and tool dimensions was not found.

\section{Rater's Information}

As shown in Figure 5, there was no big difference between safety and usability training of respondents. The most respondents replied that they had OJT concerning safety and usability, however, more than 40 percent of respondents answered that they have never had safety or usability training. 


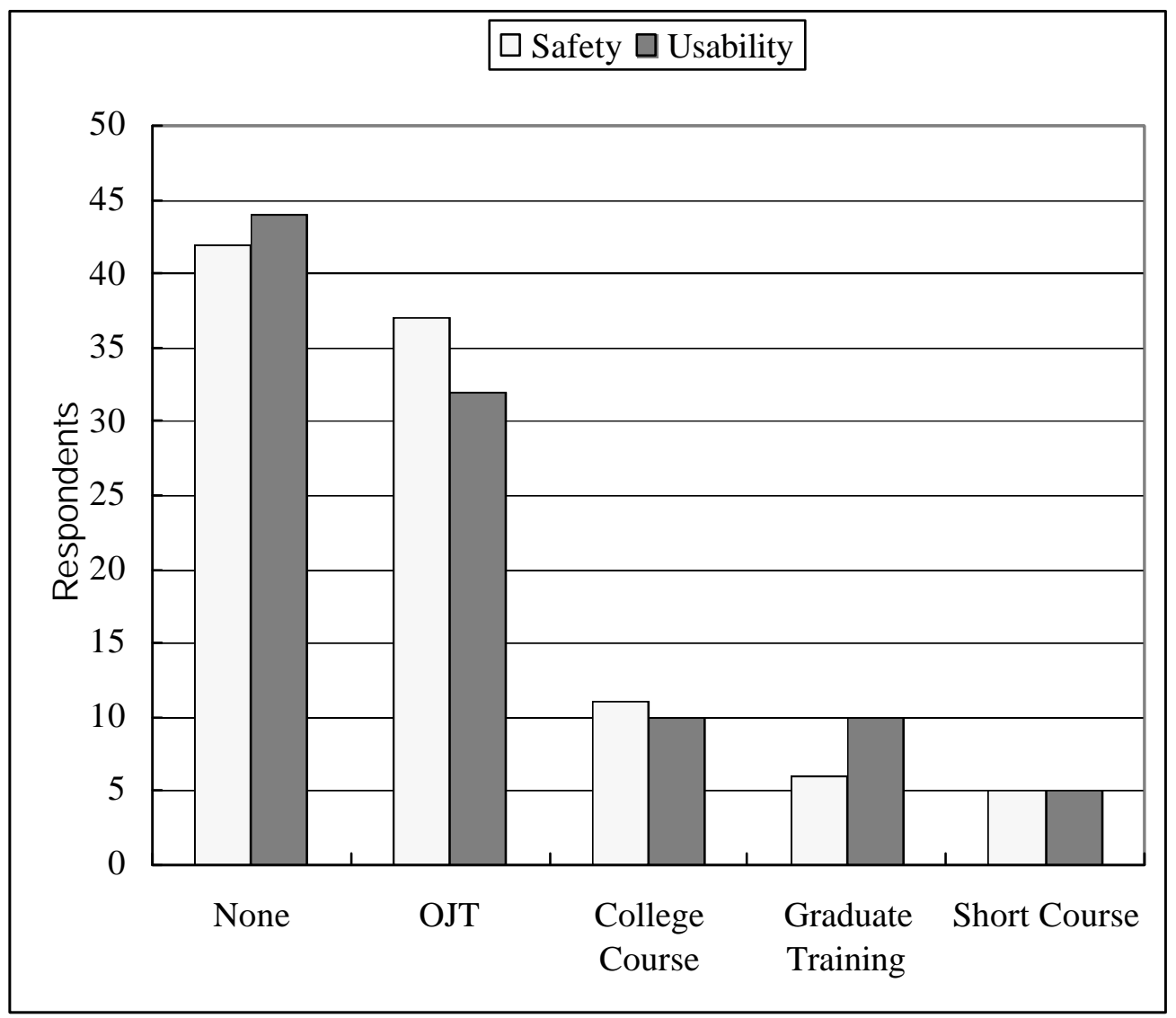

Figure 5. Comparison between Safety and Usability Training Experience of Respondents

As represented in Figure 6, more than 90 percent of subjects responded that they have never been injured by studied powered hand tools. 


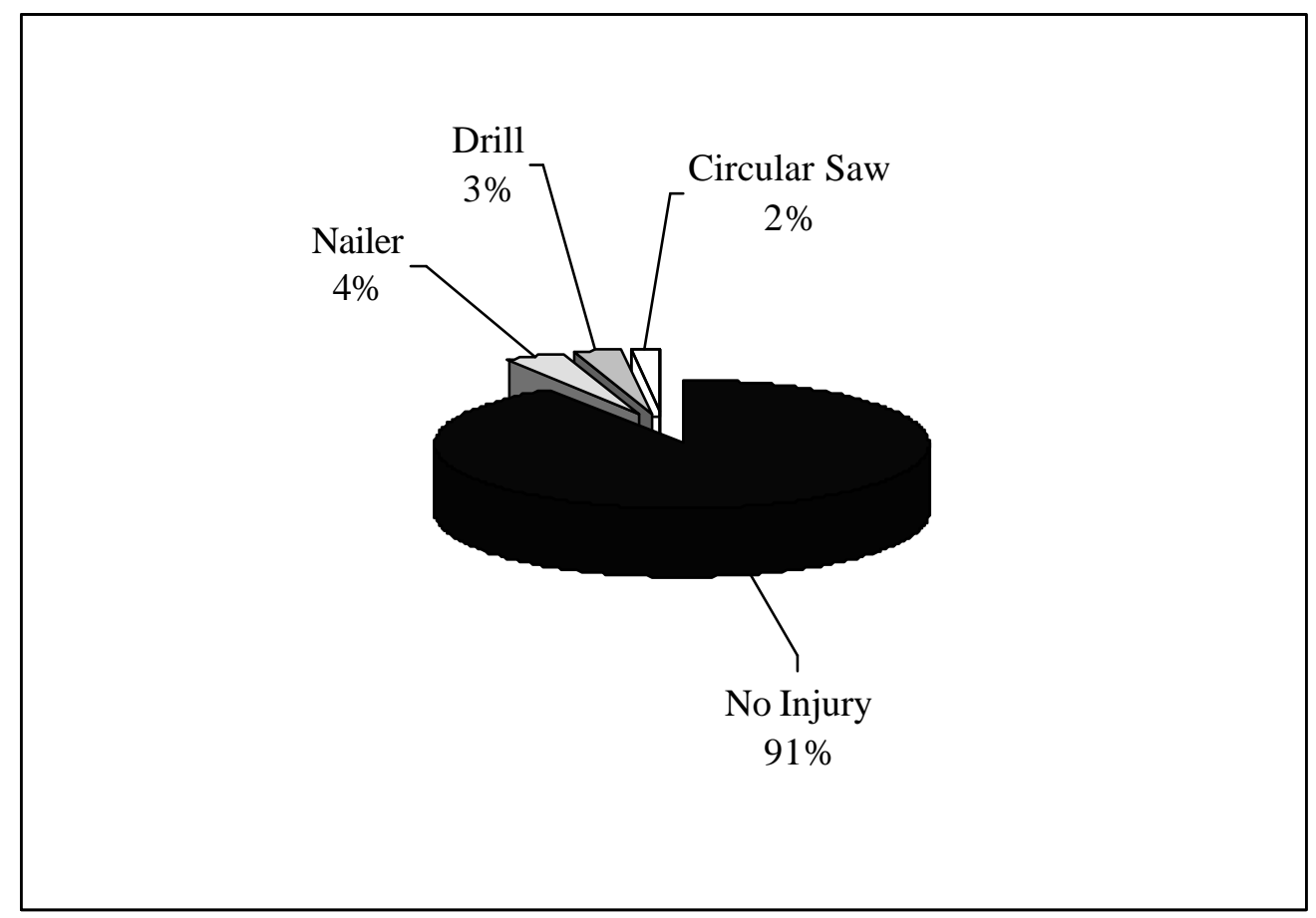

Figure 6. Percent of Raters that Experienced Injury with Powered Hand Tools Studied

\section{Tool Use Experience of Raters}

Table 4 presents how often responders use powered hand tools. Based on this survey, respondents use powered drills most frequently of the three tools studied, and nailers least frequently. Almost 30 percent of respondents uses a powered hand tool monthly at least. But about 42 percent of respondents responded that they had no powered hand tools use experience. 
Table 4. Frequency and Mean Percent of Powered Hand Tools Use of Raters

\begin{tabular}{l|rrrrr}
\hline \hline & $\begin{array}{r}\text { Circular } \\
\text { Saw }\end{array}$ & Drill & Nailer & Other Tool & $\begin{array}{r}\text { Mean } \\
\text { Percent } \\
\text { Responded }\end{array}$ \\
\hline Daily & 3 & 5 & - & 8 & $5.3 \%$ \\
Weekly & 2 & 18 & 5 & 11 & $9 \%$ \\
Monthly & 17 & 18 & 4 & 20 & $14.6 \%$ \\
Yearly & 33 & 33 & 25 & 35 & $31.5 \%$ \\
Never & 46 & 27 & 67 & 27 & $41.8 \%$ \\
\hline
\end{tabular}

\section{Rater's Confidence Using Powered Hand Tools}

Table 5 presents the means and standard deviations for each of the 11 scales across associated with rater's confidence level using powered hand tools. All means were above the midpoint of their respective rating scales other than nailers with 4.76. The highest mean was for the powered drills with 6.98 , followed by the other powered hand tools with 6.02 .

Table 5. Means and Standard Deviations of Rater's Confidence Ratings Using Powered Hand Tools

\begin{tabular}{c|cccc}
\hline \hline & Circular Saw & Drill & Nailer & Others \\
\hline Mean (SD) & $5.28(3.67)$ & $6.98(4.76)$ & $4.76(3.46)$ & $6.02(3.03)$ \\
\hline \hline
\end{tabular}

Note: Ranging Between $0=$ None and $10=$ Maximum 


\section{Perceived Usability}

Table 6 shows the means, modes, and standard deviations for each of 11 scales across 8 studied powered hand tools related to perceived usability. The mean ranges for circular saws, powered drills, and nailers were 6.45 to $7.00,6.96$ to 8.56 , and 6.17 to 7.70 respectively. The highest mean range of perceived usability for powered drills with the highest mode ranges suggest that respondents may believe that the power drills are more usable than other two powered tool categories using them. It is also interesting to note that the means for all studied tools were not significantly different.

Table 6. Means with Standard Deviations and Modes of Perceived Usability Ratings of Different Brands of Circular Saws, Powered Drills, and Nailers

\begin{tabular}{c|ccc}
\hline \hline Tool & Type & Mean (SD) & Mode \\
\hline \multirow{2}{*}{ Circular Saws } & Brand 1 & $6.45(2.82)$ & 7 \\
& Brand 2 & $7.00(2.88)$ & 8 \\
& Brand 3 & $6.73(2.79)$ & 8 \\
\hline Powered Drills & Brand 1 & $6.96(2.75)$ & 7 \\
& Brand 2 & $7.88(2.76)$ & 9 \\
& Brand 3 & $8.56(2.59)$ & 10 \\
\hline \multirow{2}{*}{ Nailers } & Brand 1 & $7.70(2.46)$ & 8 \\
& Brand 2 & $6.17(2.88)$ & 6 \\
\hline \hline
\end{tabular}


Table 7. Estimated Marginal Means of Perceived Usability Ratings of Different Brands, Genders, and Age Groups of Circular Saws

\begin{tabular}{|c|c|c|c|c|c|c|}
\hline \multirow{3}{*}{ Brand } & \multirow{3}{*}{ Gender } & \multirow{3}{*}{ Age } & \multirow{3}{*}{ Mean } & \multirow{3}{*}{ Std. Error } & \multicolumn{2}{|c|}{ 95\% Confidence Interval } \\
\hline & & & & & Lower & Upper \\
\hline & & & & & Bound & Bound \\
\hline \multirow[t]{8}{*}{1} & Male & $20-29$ Yrs & $6.90^{\mathrm{a}}$ & .38 & 6.14 & 7.66 \\
\hline & & $30-39$ Yrs & $6.42^{\mathrm{a}, \mathrm{b}}$ & .78 & 4.87 & 7.98 \\
\hline & & $40-49$ Yrs & $6.00^{\mathrm{a}, \mathrm{b}}$ & .88 & 4.25 & 7.74 \\
\hline & & $50-65$ Yrs & $6.41^{\mathrm{a}, \mathrm{b}}$ & .96 & 4.51 & 8.31 \\
\hline & Female & $20-29$ Yrs & $7.11^{\mathrm{a}, \mathrm{b}}$ & .62 & 5.89 & 8.34 \\
\hline & & 30-39 Yrs & $6.37^{\mathrm{a}, \mathrm{b}}$ & 1.36 & 3.68 & 9.06 \\
\hline & & $40-49$ Yrs & $8.78^{\mathrm{a}, \mathrm{b}}$ & 1.58 & 5.67 & 11.90 \\
\hline & & $50-65$ Yrs & $8.91^{\mathrm{a}, \mathrm{b}}$ & 1.57 & 5.80 & 12.02 \\
\hline \multirow[t]{8}{*}{2} & Male & $20-29$ Yrs & $7.40^{\mathrm{a}, \mathrm{b}}$ & .38 & 6.63 & 8.16 \\
\hline & & $30-39$ Yrs & $6.78^{\mathrm{a}, \mathrm{b}}$ & .78 & 5.23 & 8.34 \\
\hline & & $40-49$ Yrs & $7.20^{\mathrm{a}, \mathrm{b}}$ & .88 & 5.45 & 8.94 \\
\hline & & $50-65$ Yrs & $7.58^{\mathrm{a}, \mathrm{b}}$ & .96 & 5.68 & 9.48 \\
\hline & Female & $20-29 \mathrm{Y} \mathrm{rs}$ & $6.94^{\mathrm{a}, \mathrm{b}}$ & .62 & 5.72 & 8.16 \\
\hline & & 30-39Yrs & $9.12^{\mathrm{a}, \mathrm{b}}$ & 1.36 & 6.43 & 11.81 \\
\hline & & $40-49$ Yrs & $8.28^{\mathrm{a}, \mathrm{b}}$ & 1.58 & 5.17 & 11.40 \\
\hline & & $50-65$ Yrs & $8.91^{\mathrm{a}, \mathrm{b}}$ & 1.57 & 5.80 & 12.02 \\
\hline \multirow[t]{8}{*}{3} & Male & $20-29$ Yrs & $7.06^{\mathrm{a}, \mathrm{b}}$ & .38 & 6.30 & 7.82 \\
\hline & & 30-39 Yrs & $7.20^{\mathrm{a}, \mathrm{b}}$ & .78 & 5.65 & 8.75 \\
\hline & & $40-49$ Yrs & 7.20 & .88 & 5.45 & 8.94 \\
\hline & & $50-65$ Yrs & 6.71 & .96 & 4.81 & 8.61 \\
\hline & Female & 20-29Yrs & 6.64 & .62 & 5.41 & 7.86 \\
\hline & & 30-39 Yrs & 6.12 & 1.36 & 3.43 & 8.81 \\
\hline & & $40-49$ Yrs & 8.28 & 1.58 & 5.17 & 11.40 \\
\hline & & $50-65$ Yrs & 3.91 & 1.57 & .80 & 7.02 \\
\hline
\end{tabular}

a. Evaluated at covariates appeared in the model: Circular Saw Use Confidence $=6.27$, Circular Saw Usage $=4.15$

b. Based on modified population marginal mean. 


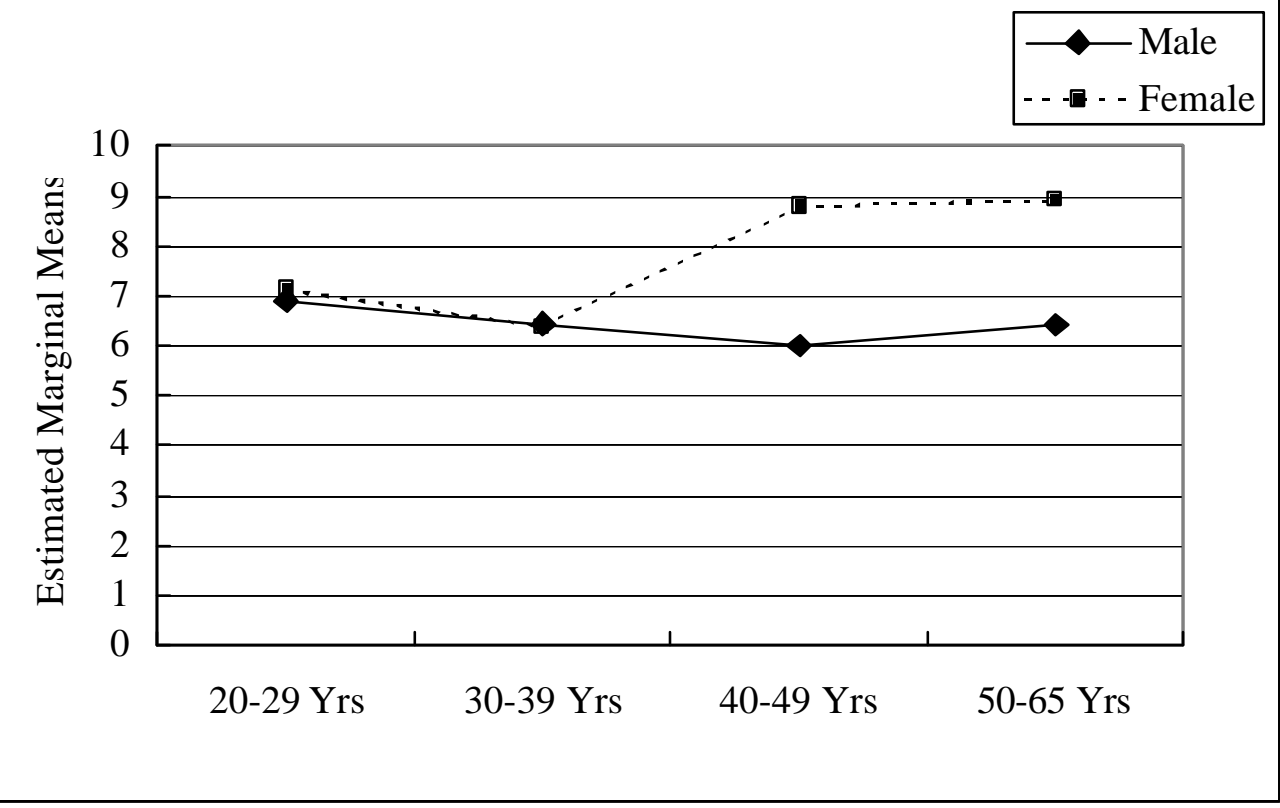

Figure 7. Estimated Marginal Means of Perceived Usability Ratings of Circular Saw, Brand 1

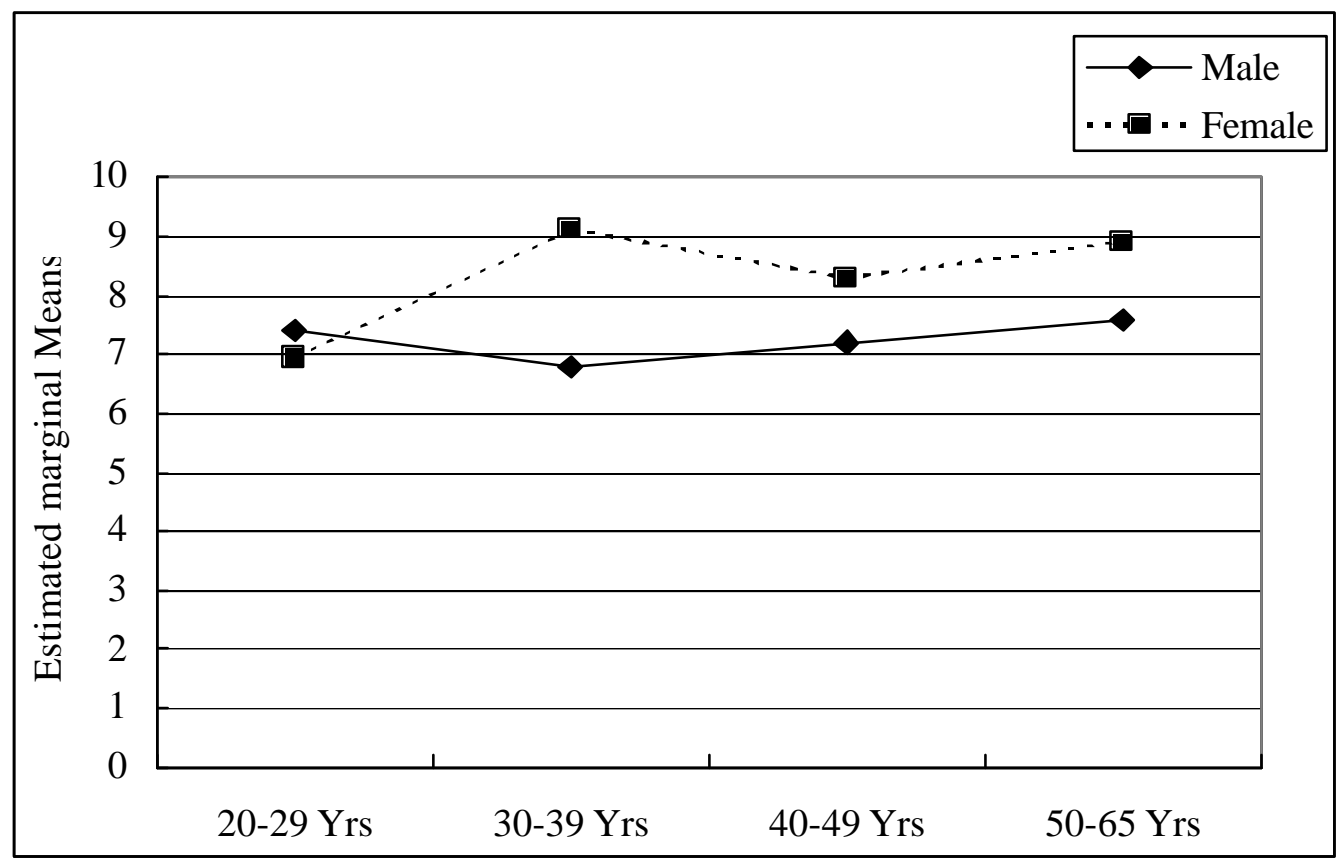

Fig ure 8. Estimated Marginal Means of Perceived Usability Ratings of Circular Saw, Brand 2 


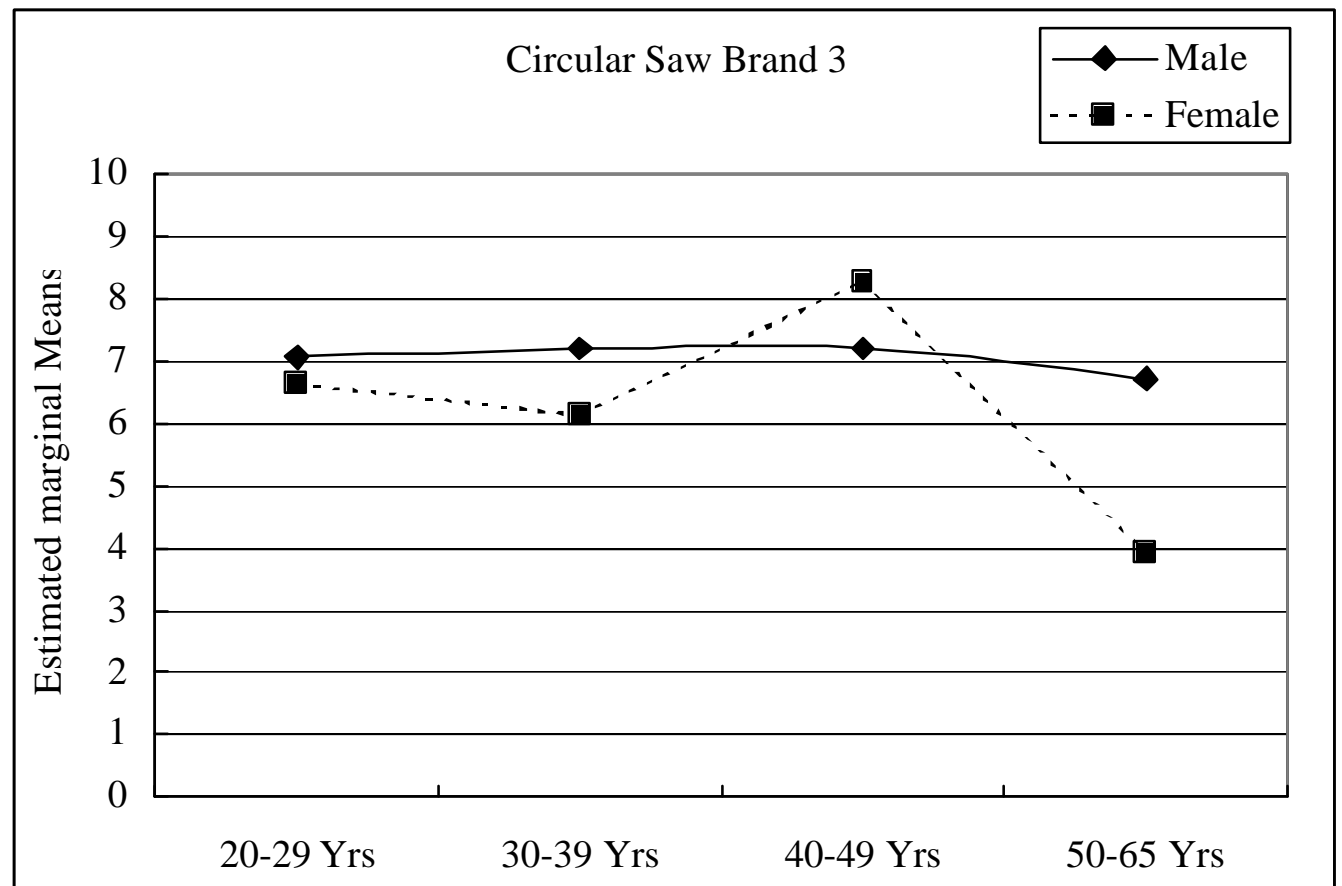

Fig ure 9. Estimated Marginal Means of Perceived Usability Ratings of Circular Saw, Brand 3

Table 7 and Figures 8 to 10 indicate the estimated marginal means of perceived usability ratings based on brand, gender, and age of different brand of circular saws. Male' estimated means stabled across all age categories, but female' estimated means fluctuated significantly. 20-29 years category showed strong consistency between male and female across all brands. The author could not make conclusions based on respondent' age and gender due to the strongly biased distribution of samples which 29 to 29 years took more than $65 \%$ and $68 \%$ of them was male. 


\section{Perceived Safety}

Table 8 reveals the means, modes, and standard deviations of perceived safety ratings of different brands of circular saws, drills, and nailers. The mean overall perceived safety ratings varied from 6.51 for the nailer (brand 2) with 2.94 of

standard deviation to 8.34 for the powered drill (brand 3) with 2.37 of standard deviation. It is interesting to note that most modes for perceived safety ratings were 8 other than 7 for the circular saw (brand 2) and for the nailer (brand 2). It means that respondents perceive almost same degree of safety for the studied powered tools. Even though the difference is very little, the relatively high means and modes for the powered drills indicate that respondents perceive higher degree of safety than that of others.

Table 8. Means with Standard Deviations and Modes Perceive d Safety Ratings of Different Brands of Circular Saws, Drills, and Nailers

\begin{tabular}{c|ccc}
\hline \hline Tool & Type & Mean (SD) & Mode \\
\hline Circular Saw & Brand 1 & $6.80(2.78)$ & 8 \\
& Brand 2 & $7.31(2.56)$ & 7 \\
& Brand 3 & $6.93(2.61)$ & 8 \\
\hline Powered Drill & Brand 1 & $7.42(2.53)$ & 8 \\
& Brand 2 & $8.06(2.41)$ & 8 \\
& Brand 3 & $8.34(2.37)$ & 8 \\
\hline Nailer/Stapler & Brand 1 & $7.92(2.15)$ & 8 \\
& Brand 2 & $6.51(2.94)$ & 7 \\
\hline
\end{tabular}


Figures 10 to 12 show the comparison between perceived safety and usability mean ratings of different brands of circular saws, drills, and nailers. Although there were slight differences, respondents' perceptions of safety and usability were almost same regardless of their brands. From this point of view, it may be concluded that the similarity of dimensions of tools studied, and the point that their images were used for this research instead of tools might contribute to the difficulty for respondents in recognizing tool's specific safety and usability features. It can be considered the weakest point of this research. In case of drills, even though the difference is not significant, respondents rated brand 3 without a cord with 8.34 and 8.56 for safety and usability respectively the most safe and usable.

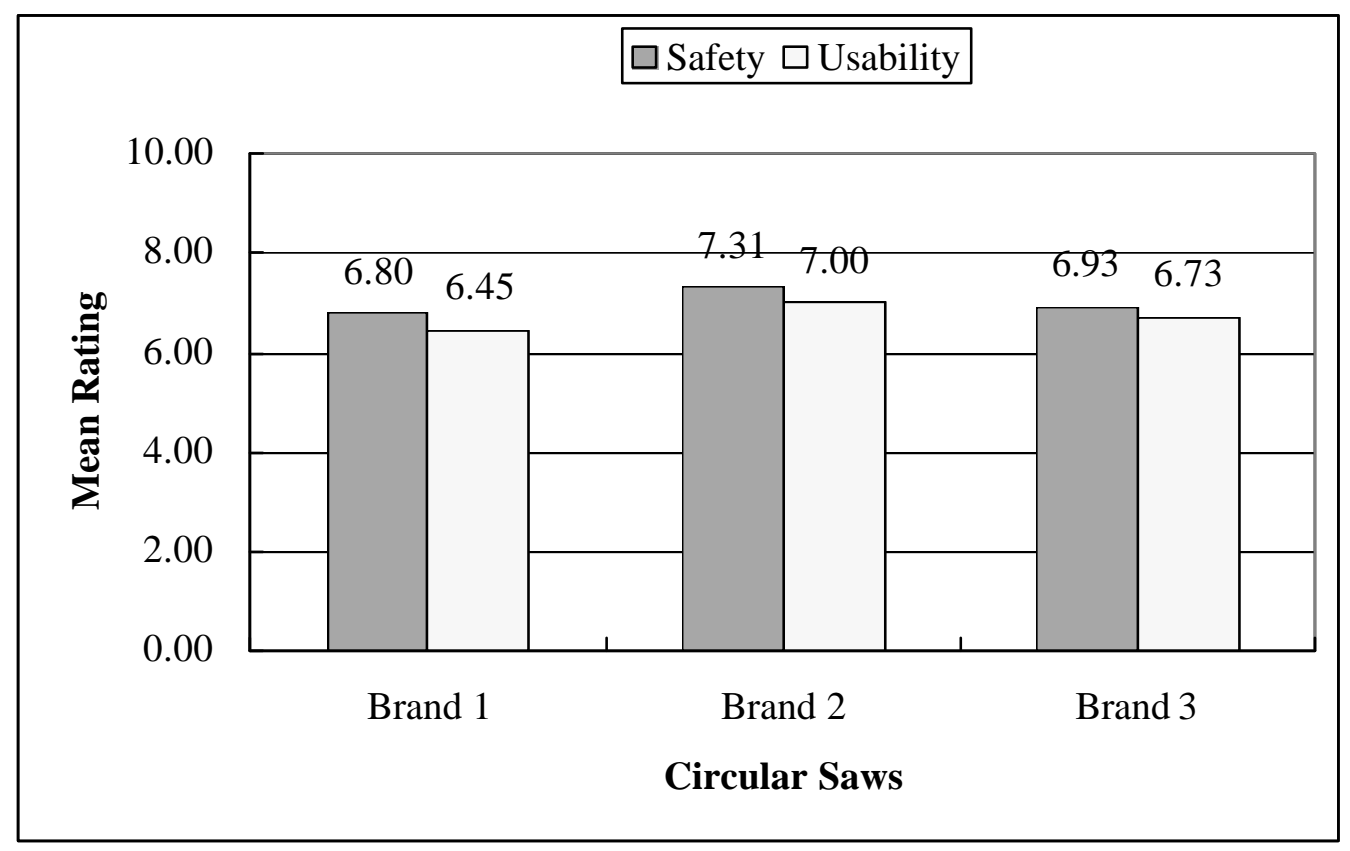

Figure 10. Comparison between Mean Ratings of Perceived Safety and Usability of Circular Saws, by Brand 


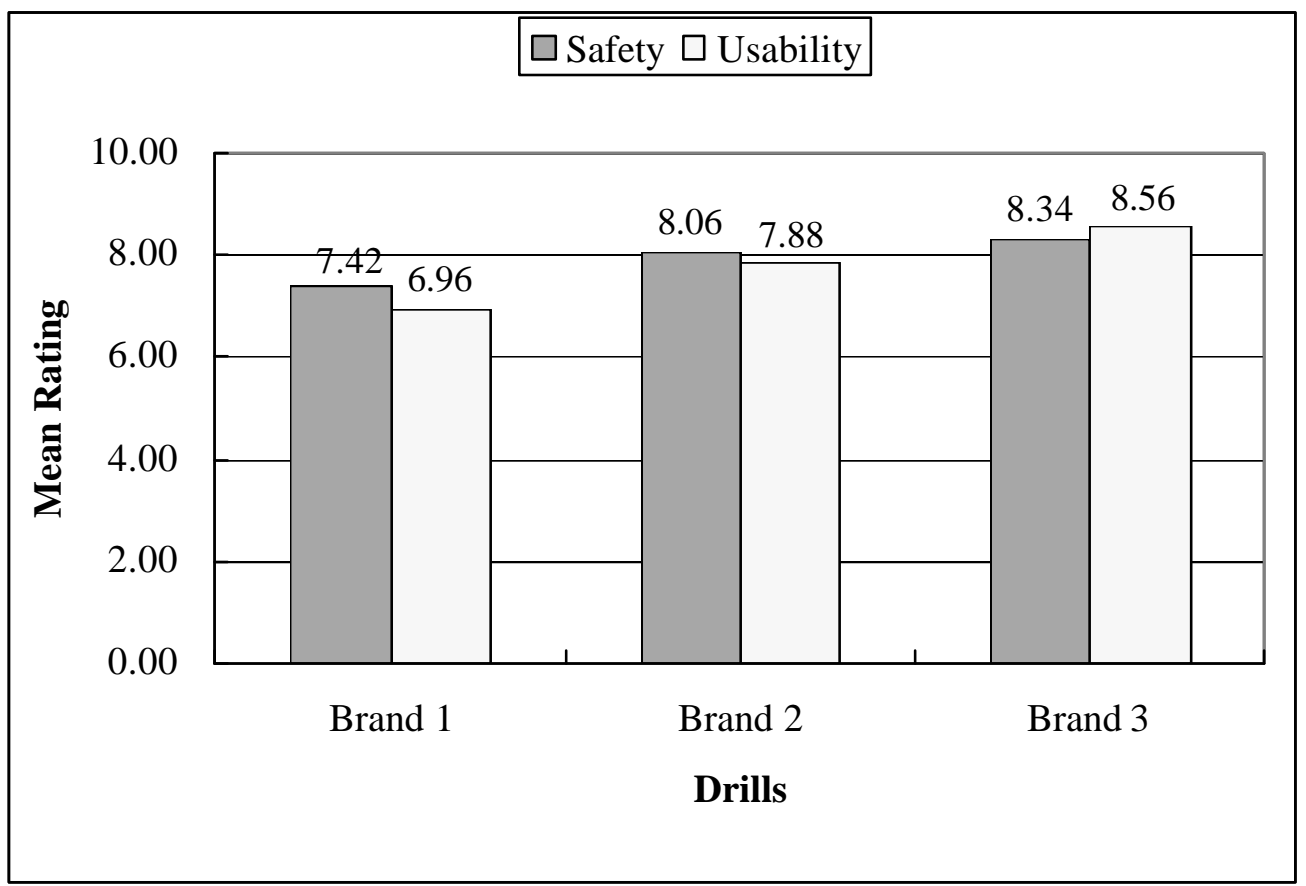

Figure 11. Comparison between Mean Ratings of Perceived Safety and Usability of Drills, by Brand

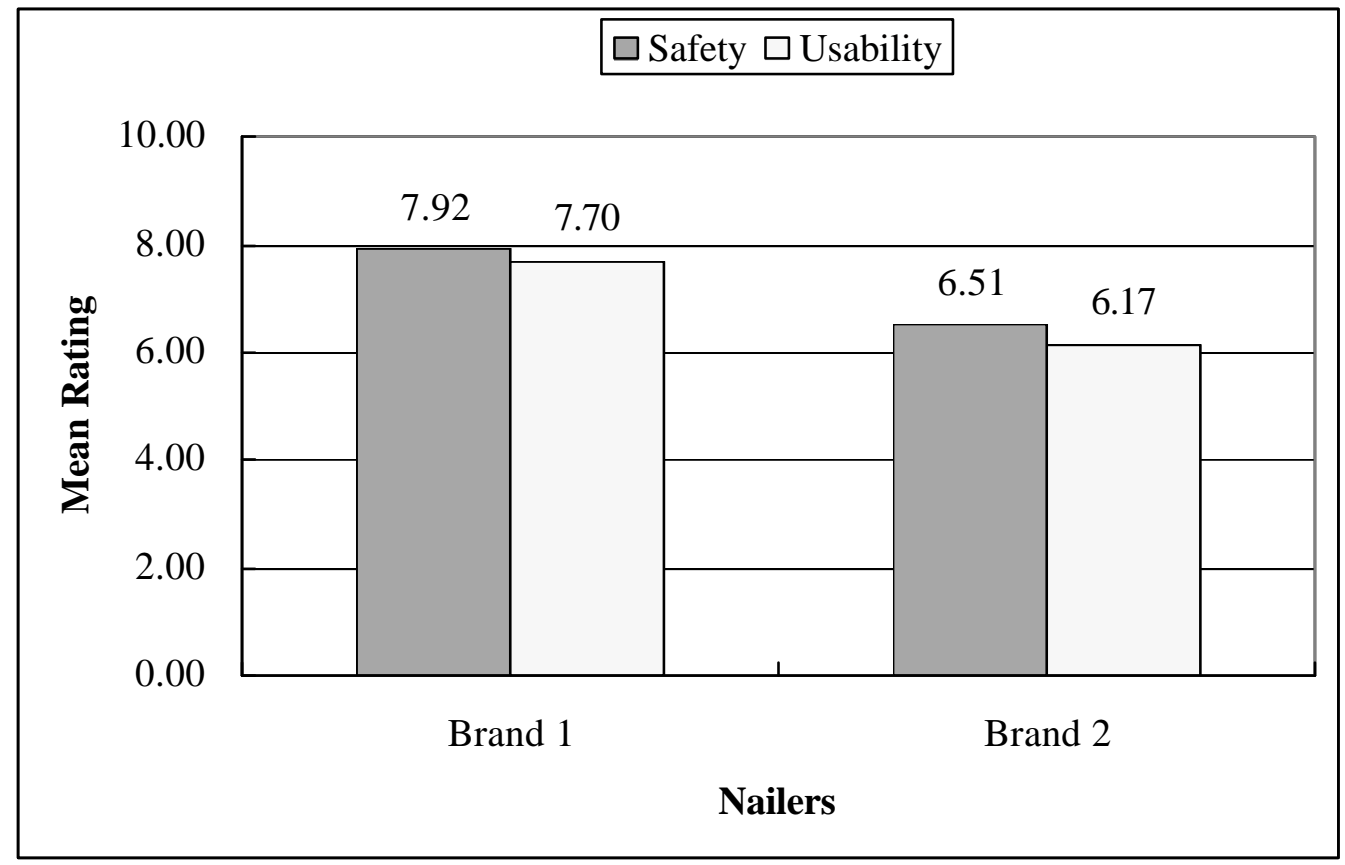

Figure 12. Comparison between Mean Ratings of Perceived Safety and Usability of Nailers, by Brand 


\section{Paired Comparison Tests of Difference between Usability Ratings of Powered Hand Tools}

As shown in Tables 9 to 11, respondents perceived usability differently according to brands and tools. In case of circular saws, the mean difference of usability between circular saw 1 and circular saw 2 was -0.55 , but the difference between circular saw 1 and circular saw 3, and circular saw 2 and circular saw 3 was -0.28 and 0.26 respectively. For the drill, the biggest difference was -1.6 between drill 1 and drill 3, the difference between drill 1 and drill 2, and drill 2 and drill 3 was -0.92 and -0.68 respectively. In case of nailers, the mean difference between nailer 1 and nailer 2 was 1.53 .

Table 9. Paired Comparison Tests of Differences between Usability Ratings of Circular Saws

\begin{tabular}{|c|c|c|c|c|c|c|c|c|c|}
\hline & & \multicolumn{5}{|c|}{ Paired Differences } & \multirow[b]{3}{*}{$\mathrm{t}$} & \multirow[b]{3}{*}{$\mathrm{df}$} & \multirow[b]{3}{*}{$\mathrm{P} \leq$} \\
\hline & & \multirow[b]{2}{*}{ Mean } & \multirow[b]{2}{*}{ SD } & \multirow[b]{2}{*}{ SEM } & \multicolumn{2}{|c|}{$\begin{array}{c}95 \% \\
\text { Confidence } \\
\text { Interval of } \\
\text { the } \\
\text { Difference } \\
\end{array}$} & & & \\
\hline & & & & & Low & Up. & & & \\
\hline Pair 1 & C/S 1 Usability & -.55 & 1.92 & .19 & -.93 & -.17 & -2.90 & 100 & .005 \\
\hline & C/S 2 Usability & & & & & & & & \\
\hline Pair 2 & C/S 1 Usability & -.28 & 2.27 & .22 & -.73 & .16 & -1.26 & 100 & .208 \\
\hline & C/S 3 Usability & & & & & & & & \\
\hline Pair 3 & C/S 2 Usability & .26 & 2.25 & .22 & -.17 & .71 & 1.19 & 100 & .236 \\
\hline & C/S 3 Usability & & & & & & & & \\
\hline
\end{tabular}


Table 10. Paired Comparison Tests of Differences between Usability Ratings of Drills

\begin{tabular}{|c|c|c|c|c|c|c|c|c|c|}
\hline & & \multicolumn{5}{|c|}{ Paired Differences } & \multirow[b]{3}{*}{$\mathrm{t}$} & \multirow[b]{3}{*}{$\mathrm{df}$} & \multirow[b]{3}{*}{$\mathrm{P} \leq$} \\
\hline & & \multirow[b]{2}{*}{ Mean } & \multirow[b]{2}{*}{ SD } & \multirow[b]{2}{*}{ SEM } & \multicolumn{2}{|c|}{$\begin{array}{c}95 \% \\
\text { Confidence } \\
\text { Interval of } \\
\text { the } \\
\text { Difference } \\
\end{array}$} & & & \\
\hline & & & & & Low & Up. & & & \\
\hline Pair 1 & Drill 1 Usability & -.92 & 1.90 & .18 & -1.29 & -.54 & -4.85 & 100 & .001 \\
\hline & Drill 2 Usability & & & & & & & & \\
\hline Pair 2 & Drill 1 Usability & -1.60 & 2.26 & .22 & -2.05 & -1.15 & -7.10 & 100 & .001 \\
\hline & Drill 3 Usability & & & & & & & & \\
\hline Pair 3 & Drill 2 Usability & -.68 & 2.15 & .21 & -1.10 & -.25 & -3.18 & 100 & .002 \\
\hline & Drill 3 Usability & & & & & & & & \\
\hline
\end{tabular}

Table 11. Paired Comparison Tests of Differences between Usability Ratings of Nailers

\begin{tabular}{|c|c|c|c|c|c|c|c|c|c|}
\hline & & \multicolumn{5}{|c|}{ Paired Differences } & \multirow[b]{3}{*}{$\mathrm{t}$} & \multirow[b]{3}{*}{$\mathrm{df}$} & \multirow[b]{3}{*}{$\mathrm{P} \leq$} \\
\hline & & \multirow[b]{2}{*}{ Mean } & \multirow[b]{2}{*}{ SD } & \multirow[b]{2}{*}{ SEM } & \multicolumn{2}{|c|}{$\begin{array}{c}95 \% \\
\text { Confidence } \\
\text { Interval of } \\
\text { the } \\
\text { Difference } \\
\end{array}$} & & & \\
\hline & & & & & Low & Up & & & \\
\hline Pair 1 & $\begin{array}{l}\text { Nailer } 1 \text { Usability } \\
\text { Nailer } 2 \text { Usability }\end{array}$ & 1.53 & 2.52 & .25 & 1.03 & 2.03 & 6.12 & 100 & .001 \\
\hline
\end{tabular}


Paired Comparison Tests of Difference between Safety Ratings of Powered Hand Tools

As revealed in Tables 12 to 14 , the results show that respondents perceived safety differently across brands and tools too. For the circular saws, the biggest mean difference was -0.50 between circular saw 1 and circular saw 2 . And there was also some difference between circular saw 1 and circular saw3, and circular saw 2 and circular saw 3, but the difference was not big as much as that between circular saw 1 and circular saw 2 . In case of drills, the biggest mean difference was -0.92 between drill 1 and drill 3. Drill 1 and drill 2 had also fairly big difference with 0.64. As shown on Table 14, respondents perceived nailer 1 safer than nailer 2 with 1.40 of difference.

Table 12. Paired Comparison Tests of Differences between Safety Ratings of Circular Saws

\begin{tabular}{|c|c|c|c|c|c|c|c|c|c|}
\hline & & \multicolumn{5}{|c|}{ Paired Differences } & \multirow[b]{3}{*}{$\mathrm{t}$} & \multirow[b]{3}{*}{$\mathrm{df}$} & \multirow[b]{3}{*}{$\mathrm{P} \leq$} \\
\hline & & \multirow[b]{2}{*}{ Mean } & \multirow[b]{2}{*}{ SD } & \multirow[b]{2}{*}{ SEM } & \multicolumn{2}{|c|}{$\begin{array}{c}95 \% \\
\text { Confidence } \\
\text { Interval of } \\
\text { the } \\
\text { Difference }\end{array}$} & & & \\
\hline & & & & & Low & Up & & & \\
\hline Pair 1 & $\begin{array}{l}\text { C/S } 1 \text { Safety } \\
\text { C/S } 2 \text { Safety }\end{array}$ & -.50 & 1.93 & .19 & -.88 & -.12 & -2.62 & 100 & .010 \\
\hline Pair 2 & $\begin{array}{l}\text { C/S } 1 \text { Safety } \\
\text { C/S } 3 \text { Safety }\end{array}$ & -.12 & 2.46 & .24 & -.61 & .35 & -.52 & 100 & .600 \\
\hline Pair 3 & $\begin{array}{l}\text { C/S } 2 \text { Safety } \\
\text { C/S } 3 \text { Safety }\end{array}$ & .37 & 2.05 & .20 & -.030 & .78 & 1.83 & 100 & .069 \\
\hline
\end{tabular}


Table 13. Paired Comparison Tests of Differences between Safety Ratings of Drills

\begin{tabular}{|c|c|c|c|c|c|c|c|c|c|}
\hline & & \multicolumn{5}{|c|}{ Paired Differences } & \multirow[b]{3}{*}{$\mathrm{t}$} & \multirow[b]{3}{*}{$\mathrm{df}$} & \multirow[b]{3}{*}{$\mathrm{P} \leq$} \\
\hline & & \multirow[b]{2}{*}{ Mean } & \multirow[b]{2}{*}{ SD } & \multirow[b]{2}{*}{ SEM } & \multicolumn{2}{|c|}{$\begin{array}{c}95 \% \\
\text { Confidence } \\
\text { Interval of } \\
\text { the } \\
\text { Difference } \\
\end{array}$} & & & \\
\hline & & & & & Low & $\mathrm{Up}$ & & & \\
\hline Pair 1 & $\begin{array}{l}\text { Drill } 1 \text { Safety } \\
\text { Drill } 2 \text { Safety }\end{array}$ & -.64 & 1.48 & .14 & -.93 & -.35 & -4.34 & 100 & .001 \\
\hline Pair 2 & $\begin{array}{l}\text { Drill } 1 \text { Safety } \\
\text { Drill } 3 \text { Safety }\end{array}$ & -.92 & 2.05 & .20 & -1.32 & -.51 & -4.50 & 100 & .001 \\
\hline Pair 3 & $\begin{array}{l}\text { Drill } 2 \text { Safety } \\
\text { Drill } 3 \text { Safety }\end{array}$ & -.27 & 1.81 & .18 & -.63 & -.08 & -1.53 & 100 & .128 \\
\hline
\end{tabular}

Table 14. Paired Comparison Tests of Differences between Safety Ratings of Nailers

\begin{tabular}{|c|c|c|c|c|c|c|c|c|c|}
\hline & & & Paire & Diffe & ences & & & & \\
\hline & & & & & $\begin{array}{r}9 \\
\text { Conf } \\
\text { Inter } \\
t \\
\text { Diffe }\end{array}$ & $\begin{array}{l}\% \\
\text { dence } \\
\text { al of } \\
\text { e } \\
\text { ence }\end{array}$ & & & \\
\hline & & Mean & SD & SEM & Low & $\mathrm{Up}$ & $\mathrm{t}$ & df & $\mathrm{P} \leq$ \\
\hline Pair 1 & Nailer 1 Safety & 1.40 & 2.57 & .25 & .89 & 1.91 & 5.49 & 100 & .001 \\
\hline & Nailer 2 Safety & & & & & & & & \\
\hline
\end{tabular}

The author did not recognize where the perception of safety and usability differences come from based on brands and tools. A further study is proposed to determine what the results would be using real tools or images ordered differently. In brief, it may be believed that there is a strong relationship between perception of safety and usability of respondents, from the strong consistency of the direction of the amount of mean difference based on brands of tools. A further detail on the relationship between the perception of safety and usability will be discussed at correlation section. 


\section{Correlations}

Figure 13 shows the relation between the perceived safety and usability ratings of circular saws having 0.71 of correlation factor. In general, respondent's safety and usability perception revealed strong positive associations.

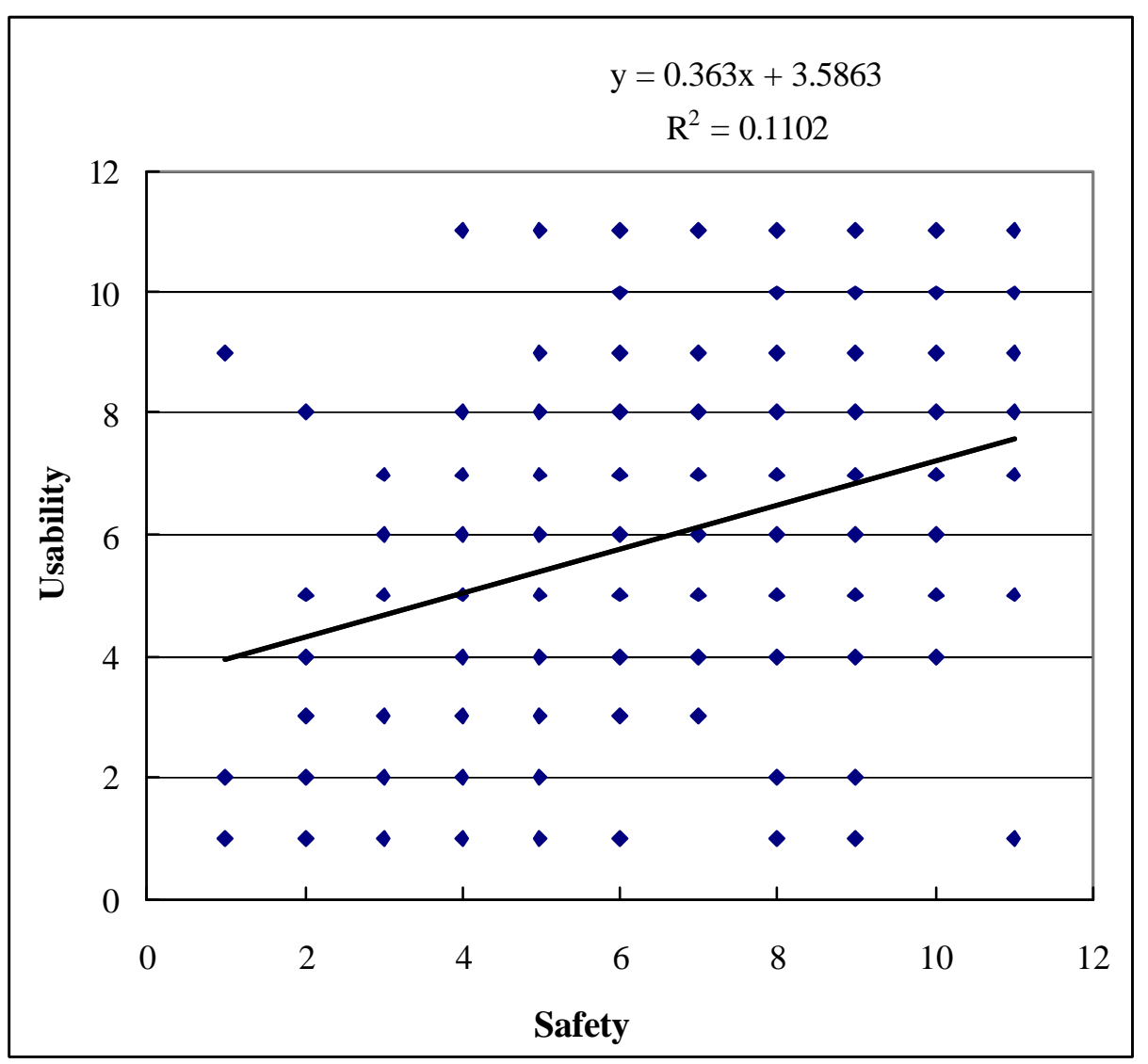

Figure 13. Scatter Plot Showing Relation between Perceived Safety and Usability Ratings of Circular Saw 
Table 15. Correlations between Respondents' Personal Factors and Perceived Safety/Usability for Circular Saws

\begin{tabular}{|c|c|c|c|c|c|c|c|c|c|}
\hline & Usability & Safety & $\begin{array}{c}\text { Circular Saw } \\
\text { Injury }\end{array}$ & $\begin{array}{c}\text { Circular } \\
\text { Saw Use } \\
\text { Confidence }\end{array}$ & $\begin{array}{c}\text { Circular } \\
\text { Saw } \\
\text { Usage }\end{array}$ & Age & Gender & $\begin{array}{l}\text { Safety } \\
\text { Training }\end{array}$ & $\begin{array}{l}\text { Usability } \\
\text { Training }\end{array}$ \\
\hline Usability & 1.00 & - & - & - & - & - & - & - & - \\
\hline Safety & 0.71 & 1.00 & - & - & - & - & - & - & - \\
\hline Circular Saw Injury & -0.02 & 0.05 & 1.00 & - & - & - & - & - & - \\
\hline $\begin{array}{c}\text { Circular Saw Use } \\
\text { Confidence }\end{array}$ & 0.59 & 0.53 & 0.13 & 1.00 & - & - & - & - & - \\
\hline Circular Saw Usage & -0.49 & -0.56 & 0.15 & -0.67 & 1.00 & - & - & - & - \\
\hline Age & 0.16 & 0.19 & 0.06 & 0.22 & -0.30 & 1.00 & - & - & - \\
\hline Gender & -0.29 & -0.27 & -0.12 & -0.40 & 0.41 & -0.18 & 1.00 & - & - \\
\hline Safety Training & 0.21 & 0.23 & 0.12 & 0.07 & -0.21 & 0.02 & -0.07 & 1.00 & - \\
\hline Usability Training & 0.24 & 0.21 & -0.01 & 0.14 & -0.18 & -0.07 & -0.18 & 0.67 & 1.00 \\
\hline
\end{tabular}


Table 16. Correlations between Respondents' Personal Factors and Perceived Safety/Usability for Drills

\begin{tabular}{|c|c|c|c|c|c|c|c|c|c|}
\hline & Usability & Safety & Drill Injury & $\begin{array}{c}\text { Drill Use } \\
\text { Confidence }\end{array}$ & Drill Usage & Age & Gender & $\begin{array}{c}\text { Safety } \\
\text { Training }\end{array}$ & Usability Training \\
\hline Usability & 1.00 & - & - & - & - & - & - & - & - \\
\hline Safety & 0.81 & 1.00 & - & - & - & - & - & - & - \\
\hline Drill Injury & 0.00 & -0.01 & 1.00 & - & - & - & - & - & - \\
\hline Drill Use Confidence & 0.62 & 0.61 & 0.06 & 1.00 & - & - & - & - & - \\
\hline Drill Usage & -0.43 & -0.48 & -0.18 & -0.66 & 1.00 & - & - & - & - \\
\hline Age & 0.14 & 0.13 & 0.19 & 0.08 & -0.30 & 1.00 & - & - & - \\
\hline Gender & -0.33 & -0.35 & -0.14 & -0.31 & 0.40 & -0.18 & 1.00 & - & - \\
\hline Safety Training & 0.27 & 0.20 & 0.14 & 0.22 & -0.29 & 0.02 & -0.07 & 1.00 & - \\
\hline Usability Training & 0.30 & 0.25 & 0.06 & 0.28 & -0.18 & -0.07 & -0.18 & 0.67 & 1.00 \\
\hline
\end{tabular}


Table 17. Correlations between Respondents' Personal Factors and Perceived Safety/Usability for Nailers

\begin{tabular}{|c|c|c|c|c|c|c|c|c|c|}
\hline & Usability & Safety & $\begin{array}{l}\text { Nailer } \\
\text { Injury }\end{array}$ & $\begin{array}{l}\text { Nailer Use } \\
\text { Confidence }\end{array}$ & $\begin{array}{l}\text { Nailer } \\
\text { Usage }\end{array}$ & Age & Gender & $\begin{array}{c}\text { Safety } \\
\text { Training }\end{array}$ & $\begin{array}{l}\text { Usability } \\
\text { Training }\end{array}$ \\
\hline Usability & 1.00 & - & - & - & - & - & - & - & - \\
\hline Safety & 0.80 & 1.00 & - & - & - & - & - & - & - \\
\hline Nailer Injury & -0.04 & -0.04 & 1.00 & - & - & - & - & - & - \\
\hline Nailer Use & 0.38 & 0.43 & 0.08 & 1.00 & - & - & - & - & - \\
\hline \multicolumn{10}{|l|}{ Confidence } \\
\hline Nailer Usage & -0.23 & -0.23 & -0.21 & -0.54 & 1.00 & - & - & - & - \\
\hline Age & 0.10 & 0.06 & 0.12 & 0.11 & -0.11 & 1.00 & - & - & - \\
\hline Gender & -0.09 & -0.17 & -0.16 & -0.24 & 0.25 & -0.18 & 1.00 & - & - \\
\hline Safety Training & 0.10 & 0.00 & 0.20 & 0.02 & -0.13 & 0.02 & -0.07 & 1.00 & - \\
\hline Usability Training & 0.05 & -0.02 & 0.02 & 0.09 & -0.11 & -0.07 & -0.18 & 0.67 & 1.00 \\
\hline
\end{tabular}


Table 18. Correlations between Tool Dimensions and Perceived Safety/Usability of Raters for Circular Saws

\begin{tabular}{cccccccccccc}
\hline \hline & $\begin{array}{c}\text { Barrel } \\
\text { Circumference }\end{array}$ & $\begin{array}{c}\text { Handle } \\
\text { Circumference }\end{array}$ & $\begin{array}{c}\text { Handle } \\
\text { Length }\end{array}$ & $\begin{array}{c}\text { Second } \\
\text { Handle } \\
\text { Circumference }\end{array}$ & $\begin{array}{c}\text { Second } \\
\text { Handle } \\
\text { Length }\end{array}$ & $\begin{array}{c}\text { Tool } \\
\text { Height }\end{array}$ & $\begin{array}{c}\text { Tool } \\
\text { Length }\end{array}$ & $\begin{array}{c}\text { Tool } \\
\text { Width }\end{array}$ & $\begin{array}{c}\text { Trigger Grasp } \\
\text { Circumference }\end{array}$ & $\begin{array}{c}\text { Trigger } \\
\text { Length }\end{array}$ & $\begin{array}{c}\text { Trigger } \\
\text { Width }\end{array}$ \\
\hline Safety & - & 0.05 & 0.06 & 0.07 & 0.03 & 0.05 & $-0.05-$ & - & $-0.06-$ & -0.08 & -0.06 \\
Usability & - & 0.03 & 0.07 & 0.08 & 0.05 & 0.06 & -0.06 & - & -0.07 & -0.08 & -0.07 \\
\hline
\end{tabular}

Table 19. Correlations between Tool Dimensions and Perceived Safety/Usability of Raters for Drills

\begin{tabular}{cccccccccccc}
\hline \hline & $\begin{array}{c}\text { Barrel } \\
\text { Circumference }\end{array}$ & $\begin{array}{c}\text { Handle } \\
\text { Circumference }\end{array}$ & $\begin{array}{c}\text { Handle } \\
\text { Length }\end{array}$ & $\begin{array}{c}\text { Second } \\
\text { Handle } \\
\text { Circumference }\end{array}$ & $\begin{array}{c}\text { Second } \\
\text { Handle } \\
\text { Length }\end{array}$ & $\begin{array}{c}\text { Tool } \\
\text { Height }\end{array}$ & $\begin{array}{c}\text { Tool } \\
\text { Length }\end{array}$ & $\begin{array}{c}\text { Tool } \\
\text { Width }\end{array}$ & $\begin{array}{c}\text { Trigger Grasp } \\
\text { Circumference }\end{array}$ & $\begin{array}{c}\text { Trigger } \\
\text { Length }\end{array}$ & $\begin{array}{c}\text { Trigger } \\
\text { Width }\end{array}$ \\
\hline Safety & -0.10 & 0.15 & -0.15 & -0.13 & -0.16 & 0.16 & -0.15 & 0.15 & - & - \\
Usability & -0.17 & 0.24 & -0.23 & -0.17 & -0.24 & 0.24 & $-0.21-$ & 0.21 & - & - & 0.15 \\
\hline \hline
\end{tabular}


Table 20. Correlations between Tool Dimensions and Perceived Safety/Usability of Raters for Nailers

\begin{tabular}{cccccccccccc}
\hline \hline & $\begin{array}{c}\text { Barrel } \\
\text { Circumference }\end{array}$ & $\begin{array}{c}\text { Handle } \\
\text { Circumference }\end{array}$ & $\begin{array}{c}\text { Handle } \\
\text { Length }\end{array}$ & $\begin{array}{c}\text { Second } \\
\text { Handle } \\
\text { Circumference }\end{array}$ & $\begin{array}{c}\text { Second } \\
\text { Handle } \\
\text { Length }\end{array}$ & $\begin{array}{c}\text { Tool } \\
\text { Height }\end{array}$ & $\begin{array}{c}\text { Tool } \\
\text { Length }\end{array}$ & $\begin{array}{c}\text { Tool } \\
\text { Width }\end{array}$ & $\begin{array}{c}\text { Trigger Grasp } \\
\text { Circumference }\end{array}$ & $\begin{array}{c}\text { Trigger } \\
\text { Length }\end{array}$ & $\begin{array}{c}\text { Trigger } \\
\text { Width }\end{array}$ \\
\hline Safety & - & 0.26 & -0.26 & - & - & -0.26 & -0.26 & 0.26 & - & - \\
Usability & - & 0.28 & -0.28 & - & - & -0.28 & -0.28 & 0.28 & - & - \\
\hline
\end{tabular}


Tables 15,16 , and 17 present the correlations between ratings for all 11 scales in relation with respondents' personal factors. In general there was a fairly high degree of correlation between safety and usability with 0.71 of correlation coefficient factor for the circular saws, 0.81 for the powered drills, and 0.80 for the nailers.

In case of circular saws and powered drills, it was revealed that respondents' use confidence and experience have strongly influenced on their safety and usability perception. The correlation factors' range between usability and use confidence was 0.59 to 0.62 , and the factors' range between safety and use confidence was 0.53 to 0.61. It suggests that respondents perceive high le vel of safety and usability having confidence in relation with the use of tools. Concerning respondents' usage, correlation coefficient factors' range was -0.43 to -0.49 for the usability, and the factors' range was -0.48 to -0.56 for the safety. In this case, it may be believed that the more experience in relation with the use of tools people have, the less safety and usability they perceive. But in case of nailers, respondents' usage and use confidence relatively less effected on their usability and safety perception with 0.38 and 0.43 of correlation factor between usability and safety, and use confidence. And it was interesting to find that there was no meaningful correlation between nailer usage, and usability and safety with -0.23 of correlation coeffic ient factors for both cases. The range of correlation factors between tool usage and use confidence for all studied tools was -0.54 to -0.67 , which may be believed that respondents with tool use experience do not have confidence for the tools.

It was surprising that there was no meaningful relationship between respondents' injury experience and safety perception. Other studied factors such as 
age, gender, and safety and usability training also did not influence on their safety and usability perception.

Table 18, 19, and 20 also indicate the correlations between ratings for all 11 scales in relation with tool dimensions such as barrel and handle circumference, second handle circumference and length, tool volume, and trigger's dimensions. No correlation was found between tool dimensions and respondent's safety and usability perception. Considering that trigger is a very important device for users' safety using tools, it was very surprising to note that triggers' dimensions such as circumference, length, and width did not disclose much differences for subjects' perception.

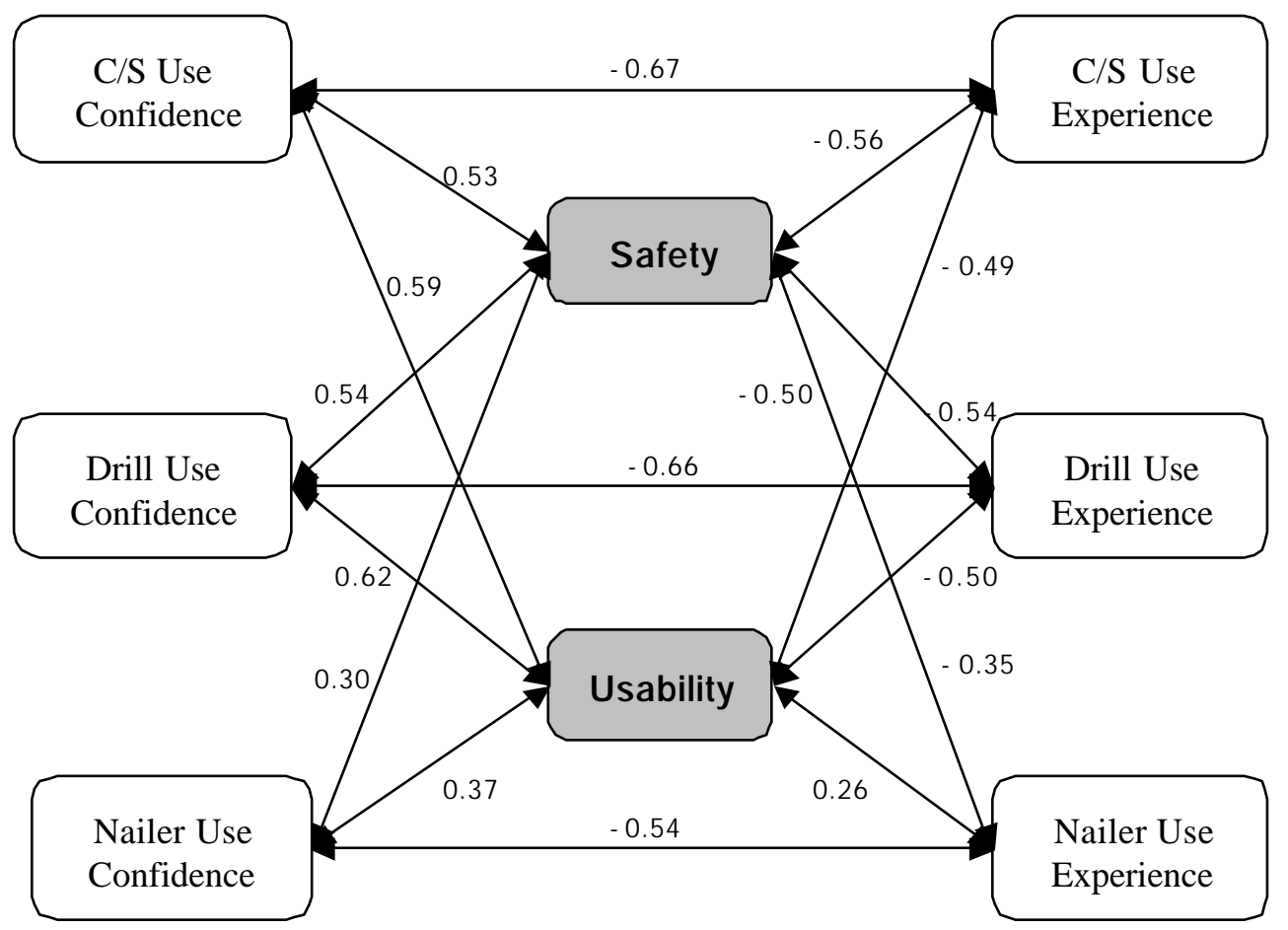

Figure 14. Inter-correlations between Personal Factors and Perceived Safety/Usability of Raters 
Figure 14 indicates the relationship between the perception of safety and usability, and personal factors of raters such as studied tool use confidence and use experience. Respondents' tool use confidence had strongly positive relation with their safety and usability perception for circular saws and drills, which suggests that the more confidence they have, the more safety and usability they perceive. But in case of relations between tool use experience and their perceptions, there were fairly high negative correlations for the circular saws and drills, which indicate that the more use experience they have, the more risk they perceive. In the nailers' case, there were no meaningful correlations between the perceptions and use confidence and experience. In general, it appears that raters' perceptions were driven by ther tool use confidence and experience.



Figure 15. Interrelationship found between Reported Injuries with Various Types of Tools 


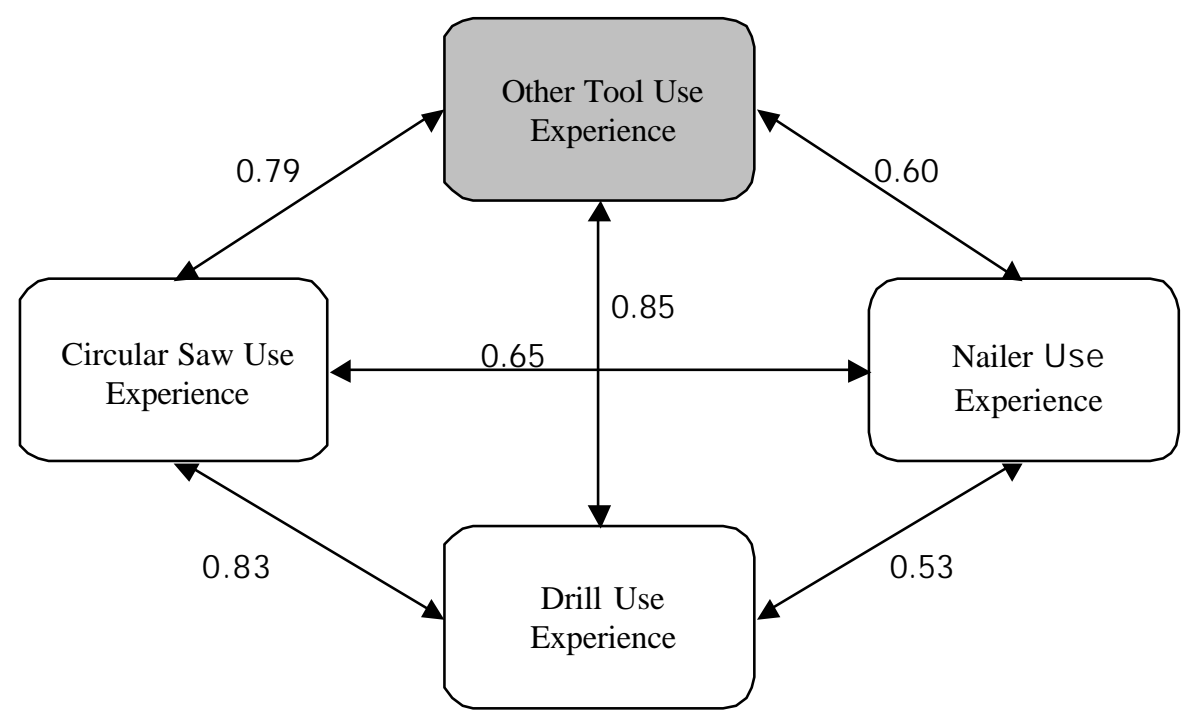

Figure 16. Correlogram demonstrating that subjects who were experienced with tools addressed in the questionnaire

As shown in Figure 15, if respondents reported high injury experiences with circular saws, powered drills, and nailers, they tend to report little injury with other tools. However, in case of studied 3 powered tools, the more injuries respondents experienced with one tool, the more injuries with powered the other two tools, or vice versa. In terms of respondents' tool use experience, as indicated in Figure 16, if subjects reported significant experience with one powered hand tool, they tended to report high experience with all tools. 


\section{CONCLUSIONS}

Respondents rated tools observed differently in terms of perceived tool usability and safety within class of tool (e.g., circular saws, powered drills and nailers). The differences in ratings appears to be driven by differences in experience and reported

confidence with use of the tools; not observed differences in tool design or dimensions or previous history of accident or injury with the tools or prior training in tool usability or safety.

Differences in design features were small and fairly consistent amongst the tools studied. Thus, without material variation in those dimensions, they are not likely to demonstrate any significant effects on observers' ratings. This may be simply an artifact of the tool designer's propensity to design within a common set of design guidelines for handles, triggers, guards, and so forth. This design inclination may be related to prevent designers' or manufacturers' liability by incorporating similar design features into the products they design and produce. The researcher would not make strong conclusions about the lack of importance of these design features-just note that there is comparatively little variation in the meas urements to save the dimensions of the tool. It is also interesting that a second handle didn't promote any change in the observer's perceptions.

Ratings of usability and safety and reports of tool use experience and confidence were highly related; indicating that if the respondent had experience and confidence with the tool, they tended to report the tool to be more usable and safe. If this is the case, users of tools may initially misjudge the usability or safety of tools if 
they appear to be similar to those tools with which they have used regularly or have confidence in using. Manufacturers should consider this when designing their tools or when considering training and warning systems for their products. 


\section{RECOMMENDATIONS}

Manufacturers and designers should make efforts to capitalize on the facts that there is a high degree of relationship between safety and usability perception. Tools that have demonstrated greater usability are also perceived as safer and vice versa.

If a tool behaves differently than tools that users may have developed experience and confidence in, then special care should be taken to warn the user of such changes. Positive transfer of experience and confidence, and associated perceptions of usability and safety, to a more challenging or hazardous tool, can be problematic.

These findings should be validated with haptic and actual use of tools. Reports are likely to differ after initial operation and handling. However, if the perceptions differ, then over estimation of tool usability and safety before use, then risk of accident or injury can increase. 


\section{REFERENCES}

Baber, C., (2002). Subjective Evaluation of Usability, Ergonomics, 14:1021-1025.

Brauer, R. L. (1996). Risk Management and Assessment, Safety and Health for Eng ineers, John Wiley \& Sons, Inc., New York: 527.

Brown, U. and O'Cass, A. (2004). The Effect of Consumer Risk Perceptions and Information Search on Willingness to Buy GM Food products: A Cross Cultural Analysis, The University of Newcastle, Newcastle, UK: 1-7.

Brian E. (2002). Risk Perception and Risk Tolerance in Aircraft Pilots, U.S. Department of Transportation (Federal Aviation Administration). Washington DC: 1-13.

Chaudhuri, A. (2000). A Marco Analysis of the Relationship of Product Involvement and Information Search: The Role of Risk, Journal of Marketing Theory and Practice, 8(1): 1-15.

Christopher. P. N. (2003). Human Factors Methods for Design, CRC Press, Washington DC: 264-265.

CPSC (2002). U.S., Consumer Product Safety Commission Annual Report to Congress, Consumer Product Safety Commission, Washington DC

CPSC (2004). U.S., Consumer Product Safety Commission Annual Report to Congress, Consumer Product safety Commission, Washington DC

Cooper, D. (2003). Psychology, Risk and Safety, Professional Safety (November): $39-46$.

Godfrey, S. S., Allender, L., Laughery, K. R., and Smith, V. L. (1983). Warning Messages: Will the Consumer Bother to Look? In Proceedings of the 27th Annual Meeting of the Human Factors Society, Human Factors Society: 950954, quoted in LaRue, C., and Cohen, C. C. (1987). Factors Affecting 
Consumers' Perceptions of Product warnings: An Examination of the Differences between Male and Female Consumers, In Proceedings of the 31st Annual Meeting of the Human Factors Society, Human Factors Society: 610614, quoted in Wogalter, M. S., Brelsford, J. W., Desaulniers, D. R., \& Laughery, K. R. (1991). Consumer Product Warning: The Role of Hazard Perception. Journal of Safety Research, 22: 71-82.

Han, S. H. and Hong, S. W. (2003). A Systematic Approach for Coupling User Satisfaction with Product Design, Ergonomics. 46: 1441-1461.

Jack, O. P. (1991). Acceptable Risks? Professional Safety (May): 32-36.

James, L. (1991). Risk Taking: Perspectives and Intervention, Professional Safety (November): 38 .

James R. L. (1994). Sample Sizes for Usability Studies: Additional Considerations, Human Factors 36(2): 368-378.

Jury Verdict Research (2004). Verdicts, Settlements and Statistical Analysis, LRP Publications, Horsham, PA

Karl, D. and Aaron, W. (1996). Theories of Risk Perception: Who Fears What and Why? University of Michigan Press, Ann Arbor, MI: 41-61.

National Research Council (1989). Improving Risk Communication: Understanding Hazards and Risks, Washington DC: 31-53.

Rockwell, T. H., Galbreath, F. D., and Center, D. H. (1961). Risk Acceptance Research in Man-Machine System. Ohio State University Bulletin: 187.

Rosa, E. A. (2003). The logical Structure of Social Amplification of Risk Framework, Cambridge University Press, Cambridge, UK.

Schmidt, J. B. and Spreng, R. A. (1996). A Proposed Model of External Consumer Information Search, Academy of Marketing Science, 24(3): 246-259. 
Slovic, P. (1987). Perception of Risk, Science 236(4799): 280-285.

SjÖberg, L., Moen, B., and Rundmo, T. (2004). Explaining Risk Perception; An Evaluation of the Psychometric Paradigm in Risk Perception Research, Norwegian University of Science and Technology, Trondheim, Nor : 7-11.

Slovic, P., Fischhoff, B., and Lichtenstein, S. (1979). Rating the Risk, Environment, 21(3): 14-20 and 36-39.

Stanton, N. A. and Barber, C. (1992). Usability: Concept, Practice and its Relationship with EC Directive 90/270/EEC. Displays 13(3): 151-160.

Stanton, N. A. and Barber, C. (1996). Factors Affecting the Selection of the Methods and Techniques Prior to Conducting a Usability Evaluation, Usability Evaluation in Industry, Taylor \& Francis, London.

Stanton, N. A. (1998). Human Factors in Consumer Products, Taylor \& Francis, Bristol, PA: 9-11.

Starr C. (1969). Science 165: 1232.

Tamerin, J. S., and Resnik, H. P. (1972). Risk Taking by Individual Option: In Perspective on Benefit-Risk Decision Making, National Academy of Engineering: 73-84.

Tversky, A. and Kahneman, D. (1973). Availability: A Heuristic for Judging Frequency and Probability. Cognitive Psychology, 5: 207-232.

Weinstein, N. D. (1989). Unrealistic Optimism about Future Life Events. Social Psychology, 39(5): 806-820.

Welford, A. T. (1959). Skill and Age, , Oxford University Press, $2^{\text {nd }}$ Edition, New York.

Weiss, D. E. (1991). The Great Devide: How Males and Females Differ, Poseidon Press. 
Wogalter, M. S., Young, S. L., Brelsford, J. W., and Barlow, T. (1999). The Relative Contributions of Injury Severity and Likelihood Information on HazardRisk Judgment and Warning Compliance, Journal of Safety Research, 30(3): 151162.

Wogalter, M., Desaulniers, D., and Brelsford, J. Jr. (1987). Consumer Products:

How are Hazards Perceived? Proceedings of the Human Factors Society $31^{\text {st }}$ Annual Meeting. Human Factors Society: 615-619.

Wogalter, M. S., B rems, D. J., and Martin, E. G. (1993). Risk Perception of Common Consumer Products: Judgments of Accident Frequency and Precautionary Intent, Journal of Safety Research, 24: 97-106.

Wogalter, M. S., Jarrard S. W., and Simpson S. N. (1994). Influence of Warning Label Signal Words on Perceived Hazard Level, Human Factors, $36(3): 547-556$.

Young, S. L., Wogalter, M. S., and Brelsford, J. W. (1992). Relative Contribution of Likelihood And Severity of Injury to Risk Perceptions. Proceedings of the 36th Annual Meeting of the Human Factors and Ergonomics Society: 10141018.

Zeitlin, L. R. (1994). Failure to Follow Safety Instructions: Faculty Communication or Risky Decisions? Human Factors, 36(1): 172-181. 


\section{APPENDIX I. Questionnaire Perceived Safety and Usability of Powered Hand Tools}

\section{Instructions}

Please provide responses to the best of your ability. You can take as long as you like to complete the questionnaire. Please submit only one questionnaire response.

Please provide an email address if you want to compete for $\mathbf{5 0 0}$ cash gift.

E-mail*

\section{Rater Information}

This web-based survey is being conducted by Professor Steven F. Wiker and Mr. Munsu Seol of the West Virginia University Ergonomics Laboratory, Department of Industrial and Management Systems Engineering, PO BOX 6070, West Virginia University, Morgantown, WV 26506.

\section{Purpose:}

This survey is designed to assess your perception of hand tool usability and safety based solely upon viewing the design and features of the tool. Each tool displayed in the questionnaire has been evaluated by experts in terms of compliance with usability and safety design guidelines and recommendations and has received a usability score and a safety score. You will be asked to visually inspect photographic images of a set of tools and to provide your estimate of the ease of use of the tool as well as an estimate of the risk of being injured when using the tool. We will compare your 
ratings against those of the experts' to see if you can recognize differences in usability and potential hazards among the tools.

The general goal of this research is to provide information that will help in the design of tools that do not create inaccurate impressions of safety or usability.

\section{Effort Required:}

Completion of the survey is voluntary and should take approximately 15 minutes to complete. Simply answer questions as you wish. After a few questions about your background and experience with use of powered hand tools and educational level in usability and safety, you will be asked to look at photos of tools and rate your impression of their ease of use and potential hazardousness.

\section{Payment:}

You will not receive any money to complete this form. However, a random selection will be made of all submissions and that individual will receive $\$ 500.00$. To receive the payment, we will need an email address to reach you.

\section{Confidentiality:}

All email addresses will be treated in a confidential manner. After the random selection is made to award the $\$ 500$, all email addresses will be destroyed and your responses will be entered into a database for analysis. We will have no means to identify your responses and there will be no possibility of determining who participated in the study. 
Results of the study will be published on the webpage for the Ergonomics Laboratory, West Virginia University.

\section{Benefits:}

You will be contributing basic information about how humans perceive usability and hazard characteristics of tools. This information will help designers of tools understand which features influence human estimates of usability and hazardousness of tools. By avoiding mismatches between actual and perceived tool usability and safety, we hope to make tools safer and easier to operate.

\section{Payments:}

Participants will not be paid for completion and submission of the questionnaire. One respondent will be randomly selected to receive $\$ 500$. The probability of receiving the $\$ 500$ will be depend upon the number of respondents and will probably be very low. Thus, the chief benefit of participating in this study is your contribution to research aimed at improving tool safety and operability.

\section{Risks or Discomforts:}

No risks to your safety or health are associated with your participation. You are not required to answer all questions and you can stop your participation at any time.

\section{Consent:}

If you complete the questionnaire and submit it, we will consider your submission to indicate that you wish to participate in the study.

1. You are a: 
$\odot$ Male

$\odot$ Female

2. Your age in years is:

3. My level of training in usability is:

$\odot$ None

$\odot$ On the Job Training

$\odot$ Short Course

$\odot$ College Coursework

$\odot$ Graduate Coursework

4. My level of safety training associated with powered hand tools is:

$\odot$ None

$\odot$ On the Job Training

$\odot$ Short Course

$\odot$ College Coursework

$\odot$ Graduate Coursework

5. I have been injured in the past when using:

(Select all that apply.)

$\square$ Portable Powered Circular Saw

$\square$ Portable Powered Drill

$\square$ Portable Powered Nailer or Stapler

$\square$ Never Injured By Another Type Of Powered Hand Tool

$\square$ Never Injured By A Powered Hand Tool 


\section{Rater's Tool Use Expenience}

Please rate your level of experience with the following tools:

\begin{tabular}{|l|l|l|l|l|l|}
\hline & Daily & Weekly & Monthly & Yearly & Never \\
\hline 6. I Use Circular Saws & & & & & \\
\hline 7. I use Portable Drills & & & & & \\
\hline 8.I Use Power Nailers & & & & & \\
\hline 9. I use Other Powered Hand Tools & & & & &
\end{tabular}

\section{Rater's Confidence Using Powered Hand Tools}

Please rate your confidence in using powered hand tools noted below:

\begin{tabular}{|c|c|c|c|c|c|c|c|c|c|c|}
\hline & None & 1 & 2 & 34 & 5 & 6 & 7 & 8 & 9 & Maximum \\
\hline \multicolumn{11}{|l|}{ 10. Circular Saws } \\
\hline \multicolumn{11}{|l|}{ 11. Portable Drills } \\
\hline \multicolumn{11}{|l|}{ 12. Power Nailers } \\
\hline 13. Other Powered Hand & & & & & & & & & & \\
\hline Tools & & & & & & & & & & \\
\hline
\end{tabular}

\section{Perceived Usability}

Please press the "next" or "prev" button in the photo to forward or backward with photos. First rate your impression of each of the tools' usability--the ability to operate the tool effectively. Then repeat the process and give a rating of your impression your ability to use the tool safely. 


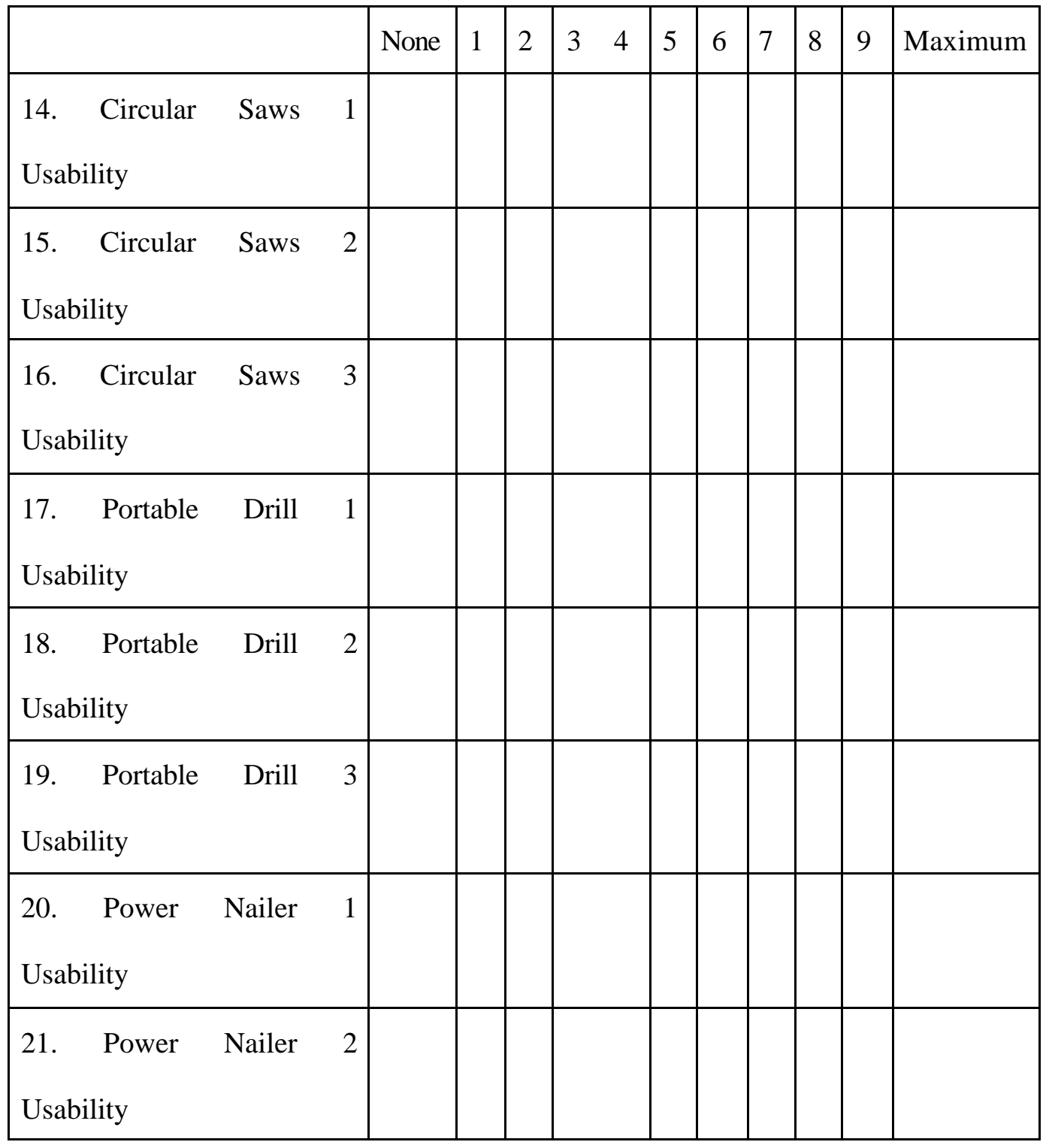

\section{Perceived Safety}

\begin{tabular}{|l|l|l|l|l|l|l|l|l|l|l|} 
& None 1 & 2 & 3 & 4 & 5 & 6 & 7 & 8 & 9 & Maximum \\
\hline 22. Circular Saws 1 Safety & & & & & & & & & & \\
\hline
\end{tabular}




\begin{tabular}{|l|l|l|l|l|l|l|l|l|l|}
\hline 23. Circular Saws 2 Safety & & & & & & & & & \\
\hline 24. Circular Saws 3 Safety & & & & & & & & & \\
\hline 25. Portable Drill 1 Safety & & & & & & & & & \\
\hline 26. Portable Drill 2 Safety & & & & & & & & & \\
\hline 27. Portable Drill 3 Safety & & & & & & & & & \\
\hline 28. Power Nailer 1 Safety & & & & & & & & & \\
\hline 29. Power Nailer 2 Safety & & & & & & & & & \\
\hline
\end{tabular}

Thank you for participating. Submit your questionnaire responses by clicking on the button below. If you see the WVU web page, we have received your questionnaire. 
APPENDIX II. Image of Tools
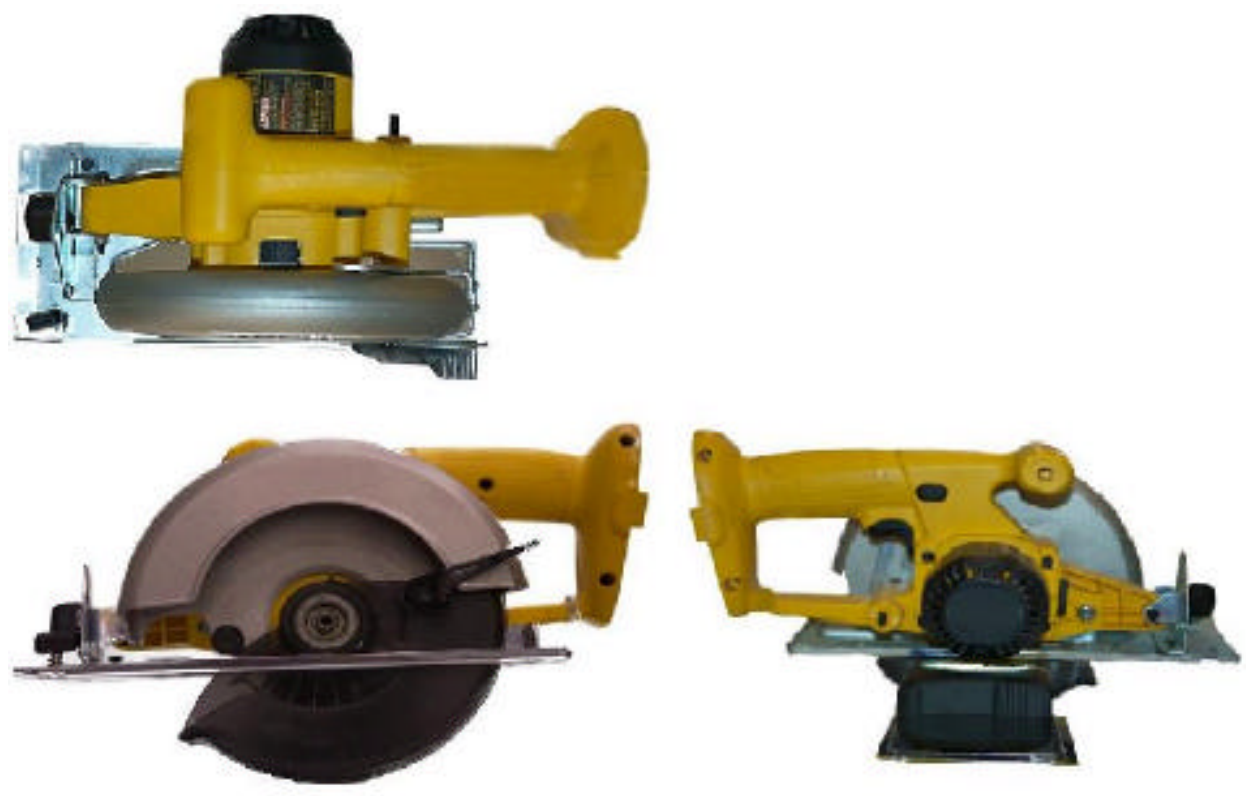

Circular Saw 1
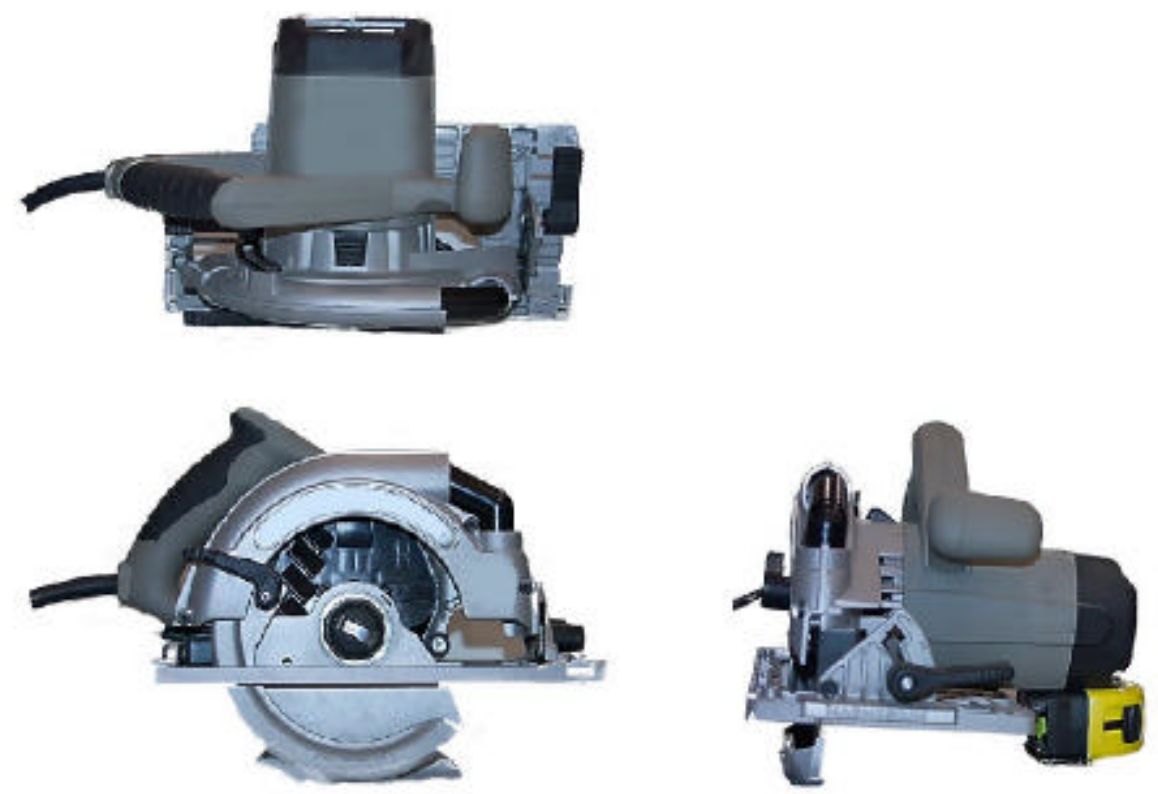

Circular Saw 2 

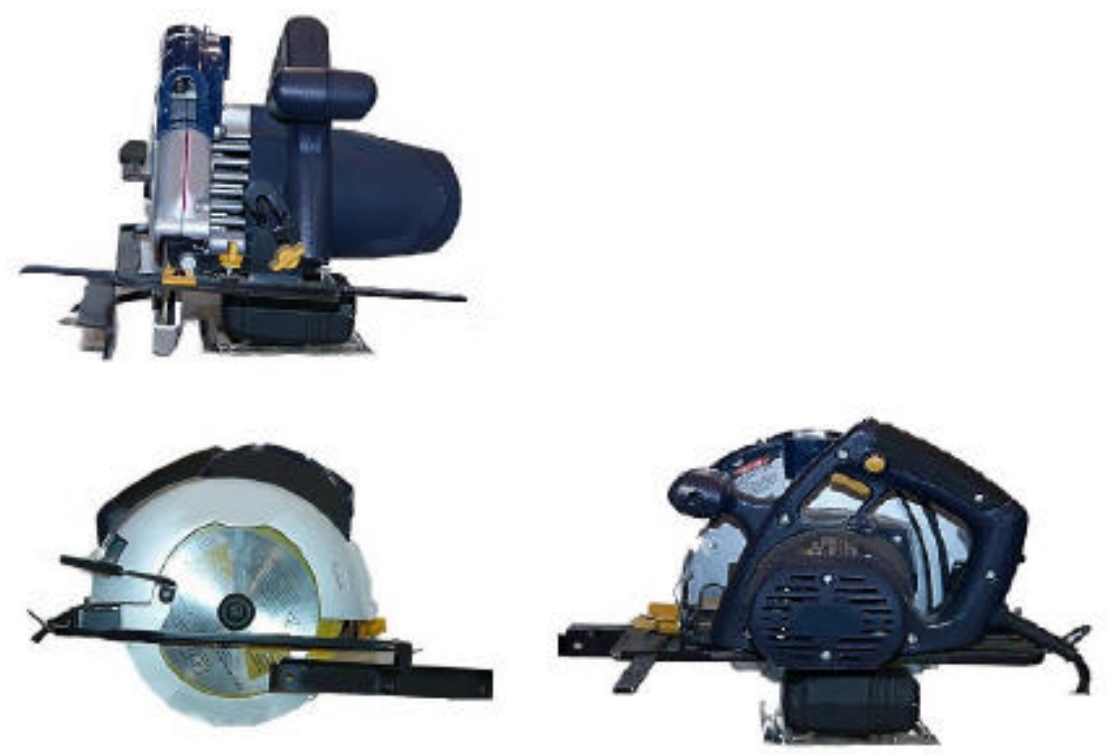

Circular Saw 3
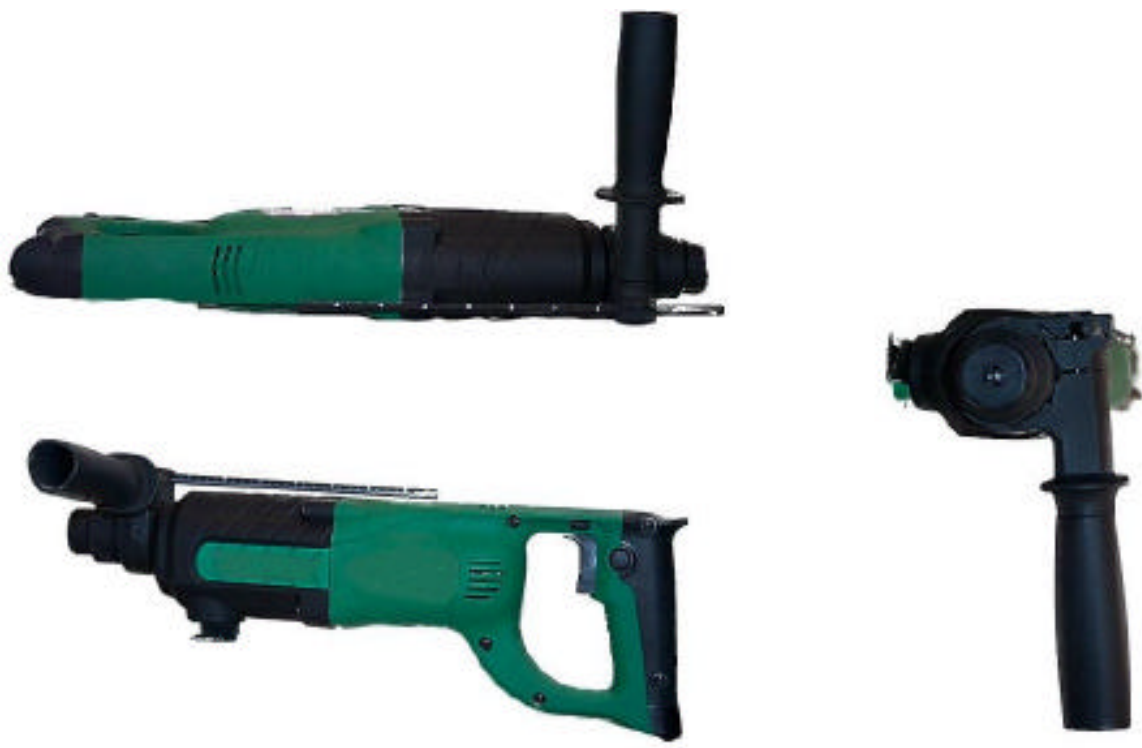

Drill 1 

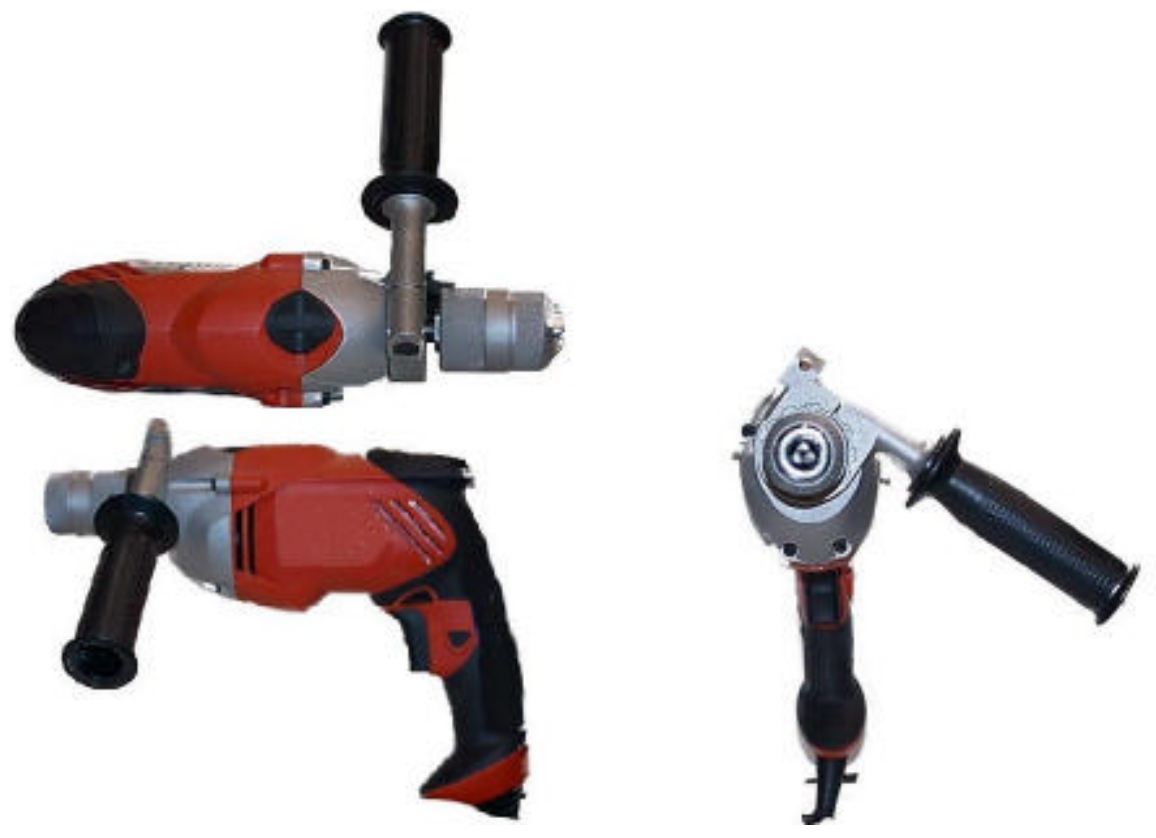

Drill 2
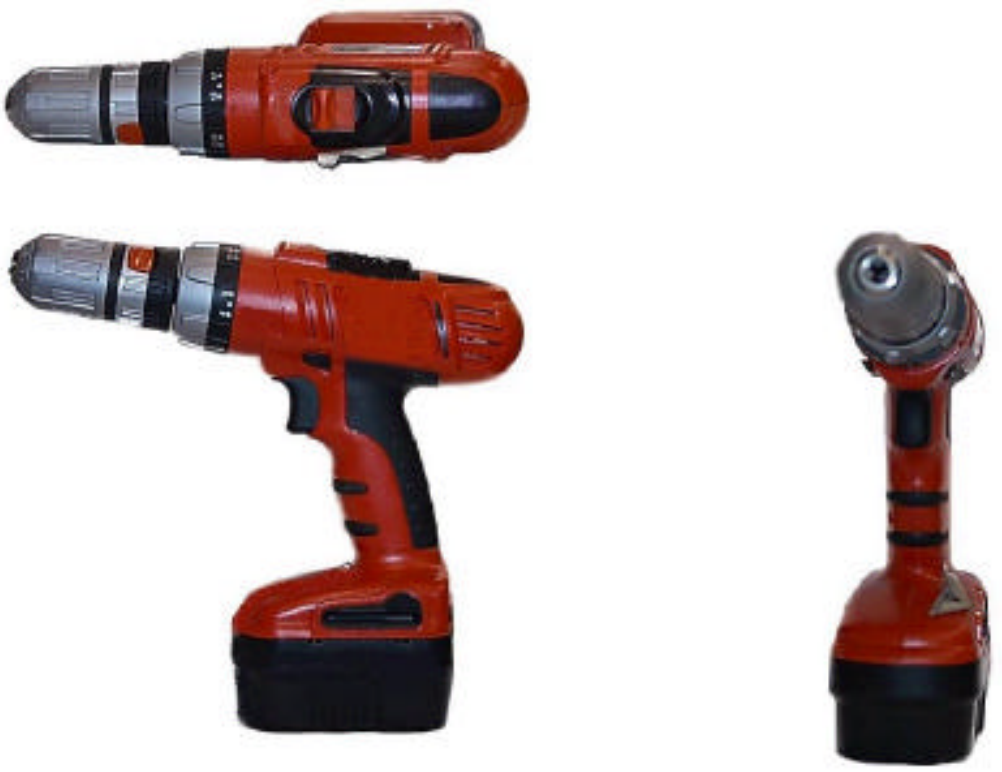

Drill 3 

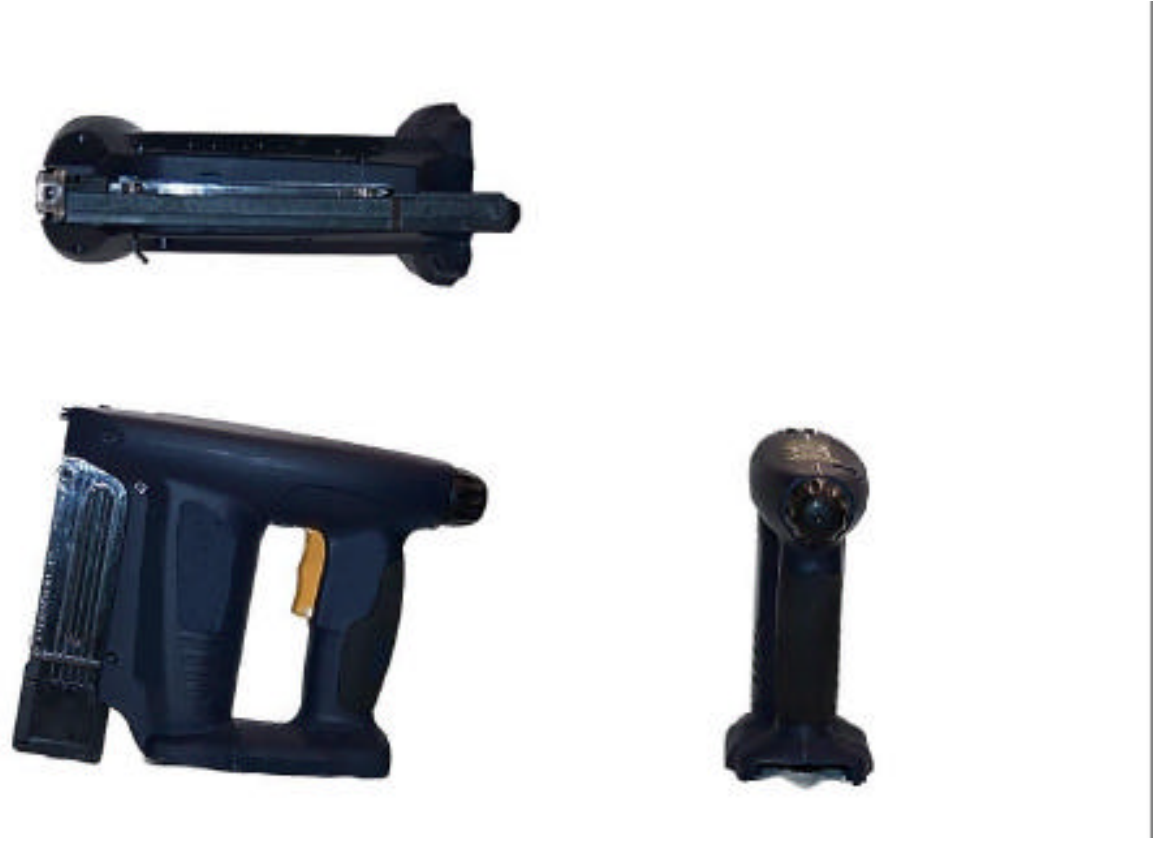

Nailer 1
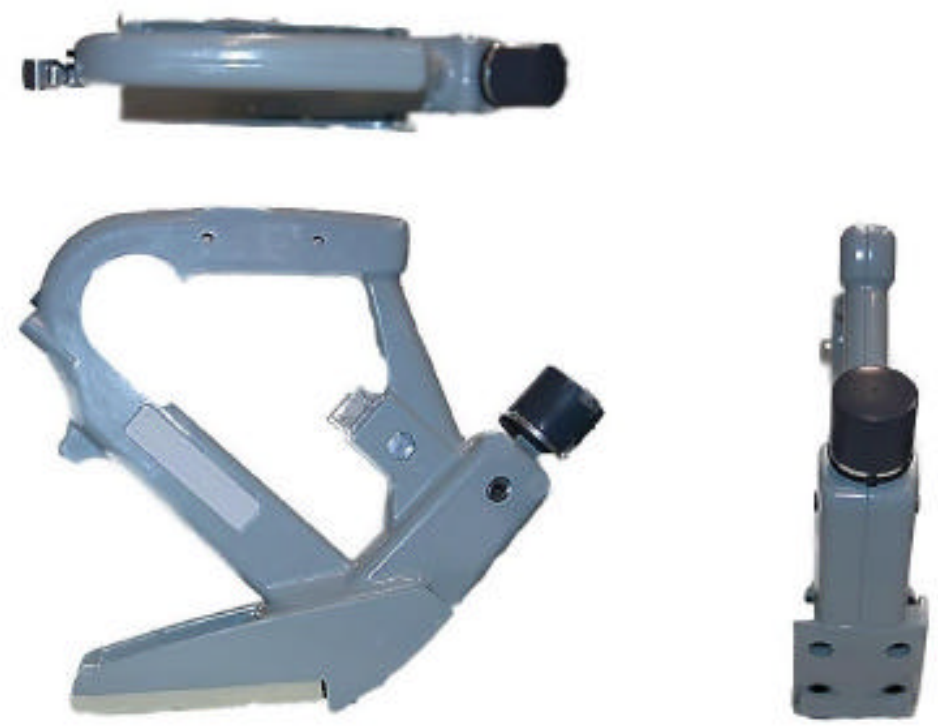

Nailer 2 


\section{APPENDIX III. Advertisement Flier}


\section{PARTICIPANTS NEEDED!}

Purpose: The Ergonomics Laboratory, West Virginia University, is conducting a study of the ability of humans to assess the usability and safety of powered hand tools simply by looking at images of the tools. We intend to use the results of this study to help improve the safety and usability of powered hand tools for usersregardless of their experience level with powered hand tools.

Effort: You will be asked to log onto the internet using any available computer, type in the internet address that presents the web-based survey and respond to the questions. You will visually inspect photographic images of a set of tools and provide your estimates of the ease of use of the tool and risk of being injured when using the tool. Completion of the survey is voluntary and should take approximately 15-20 minutes of your time. You simply answer the questions or provide ratings.

Payment: You will not receive any money to complete this form. However, a random selection will be made of all submissions and that individual will receive $\$ 500.00$. 
Confidentiality: All responses will be treated in a confidential manner. After the random selection is made to award the $\$ 500$, all email addresses provided will be destroyed and your responses will be entered into a database for analysis.

Risks or Discomforts: No risks to your safety or health are associated with your participation. You are not required to answer all questions and you can stop your participation at any time.

If you wish to participate, simply type the following into your internet browser:

http://web.cemr.wvu.edu/ ergonomicslab/HTML/handtoolsurvey.html

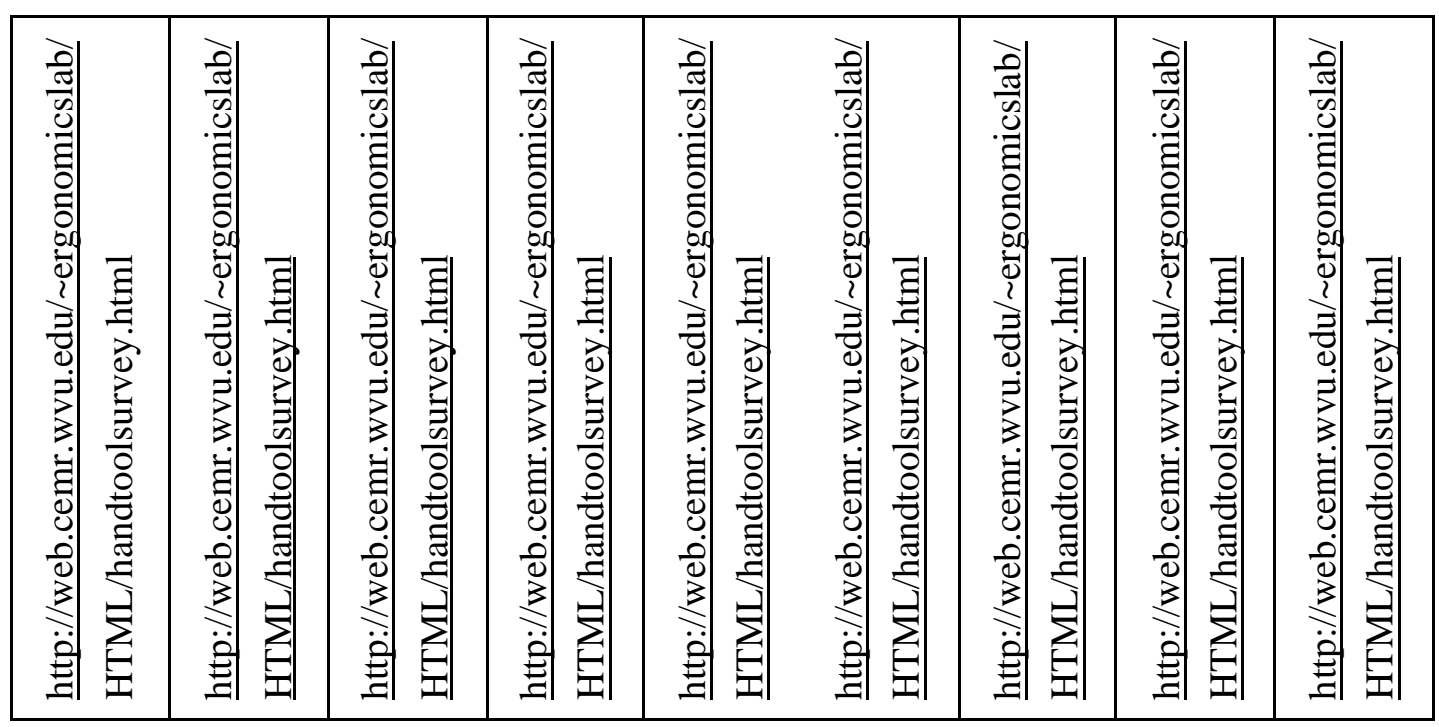




\section{APPENDIX IV}

\section{Definitions}

Accident: an event that results in unintended harm or damage

Consumer product: any article or component part thereof, produced or distributed (1) for sale to a customer for use in or around a permanent or temporary household or residence, a school, in recreation, or otherwise, or (2) for the personal use, consumption or enjoyment of a consumer in or around a permanent or temporary household or residence, a school, in recreation, or otherwise (Consumer Product Safety Act)

Hazard: a condition or set of circumstances that has the potential of causing or contributing to injury or death

Incident: an event which could or does result in unintended harm or damage

Perception: a mechanism with which a person evaluate inputs form external environment, which, in turn, determines his/her behavioral response

Risk: the product of severity of consequences of and probability of an incident

Risk perception: one's opinion of the likelihood of risk associated with performing a certain activity or choosing a certain lifestyle 
Safety: the state of being relatively free from harm, danger, injury or damages

Usability: the effectiveness, efficiency, and satisfaction with which specified users achieve specified goals in particular environments (ISO 9241) 


\title{
APPENDIX V. IRB Memorandum
}

\author{
West VrginiaUniversity \\ Office of Research Compliance
}

Date: May 10, 2005

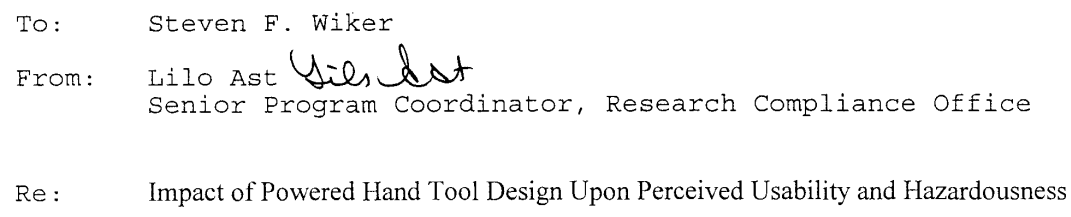

The Institutional Review Board for the Protection of Human subjects (IRB) finds the above named research project qualifies as an exemption.

This finding will remain in effect only on the condition that the research is carried out exactly as described in the Application. Please submit an amendment to the IRB office if you intend to modify or change your study in any way. Any amendment must be reviewed and acknowledged before initiating any changes or modifications.

Best wishes for the success of your research. 